“THIS IS HOW I LEARN”: CHILDREN'S PERCEPTIONS OF THEIR EXPERIENCES IN TWO DIFFERENT LEARNING ENVIRONMENTS.

by

Tiffany Barnikis

B.A. Honours

The University of Bristol, UK, 1999

\author{
A Major Research Paper \\ Presented to Ryerson University
}

In partial fulfillment of the

requirements for the degree of

\author{
Master of Arts \\ in the Program of \\ Early Childhood Studies
}

Toronto, Ontario, Canada, 2014

(C) Tiffany Barnikis, 2014 


\section{Author's Declaration}

I hereby declare that I am the sole author of this MRP. This is a true copy of the MRP, including any required final revisions.

I authorize Ryerson University to lend this MRP to other institutions or individuals for the purpose of scholarly research.

I further authorize Ryerson University to reproduce this MRP by photocopying or by other

means, in total or in part, at the request of other institutions or individuals for the purpose of scholarly research.

I understand that my MRP may be made electronically available to the public. 


\title{
“THIS IS HOW I LEARN”: CHILDREN'S PERCEPTIONS OF THEIR EXPERIENCES IN TWO DIFFERENT LEARNING ENVIRONMENTS.
}

\author{
(C) Tiffany Barnikis, 2014 \\ Master of Arts \\ Early Childhood Studies \\ Ryerson University
}

\begin{abstract}
This qualitative study explored five children's perspectives of their experiences in both a university laboratory school and in their current public school setting. Semi-structured conversations and child-produced drawings provided children with an opportunity, not only to express their thoughts and opinions, but also aided in establishing children as competent informants on their own lived experiences. Employing the 'new' sociology of childhood, critical studies, and a child rights-based perspective as theoretical frameworks, an overarching theme of power and hierarchy was established throughout the children's descriptions of their experiences. More specifically, this central theme is explored through the children's discussions and descriptions of: space, pedagogical practice, peer relationships, rules, and their decision-making and influence on curriculum. These themes, however, present themselves differently in the children's implicit and explicit comparisons of the different learning environments. In conclusion, recommendations for future practices and areas for further research are discussed.

Keywords: children's perception of education, 'new' sociology of childhood, critical pedagogy, kindergarten, university laboratory schools
\end{abstract}




\section{Acknowledgements}

The following people offered support and guidance that was integral to the completion of this project. Thank you for believing in me along this journey.

I would first like to thank the children who participated in this study. Thank you for taking the time to speak with me. This project would not be possible without your words. I hope this project honours your perceptions and experiences.

Thank you to my supervisor, Dr. Rachel Berman. Your support has been fundamental to the completion of this project. Thank you for believing in, and encouraging me throughout all stages of this process. Thank you for the countless hours spent reading, editing, conversing, supporting and guiding. Through your guidance and mentorship, I find myself intrigued and enthused about pursuing future research. I truly appreciate all that you have done.

Thank you to my second reader, Dr. Rachel Langford. Thank you for your willingness to review and to critically examine this research study. Your comments and time are much appreciated.

Thank you to Dr. Mehrunnisa Ahmad Ali. Thank you for your support and guidance as the Director of the graduate program, and as a member of my defense committee.

I would like to thank my family and friends for their moral support and encouragement. Thank you to my parents for supporting and believing in me along this journey. Thank you to my husband Craig for the countless hours of discussion, and reading (draft after draft). Your support, at times, may have gone unacknowledged, but never unappreciated. I could never have done this without you. Thank you to my son Camden for inspiring this project and for always having a hug ready when I needed it the most. I am who I am today, because of all of you. 


\section{Dedication}

For my Grandma, Margery Bennett, who helped to fill my childhood with so many wonderful memories. You were not able to see the completion of this journey, however, I know you would have been proud.

For my son, Camden. You inspire and encourage me in so many ways. May you always feel heard, valued and respected. 


\section{Table of Contents}

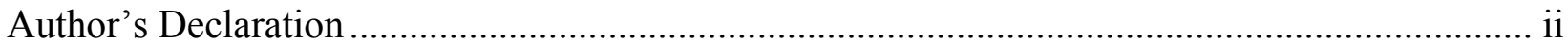

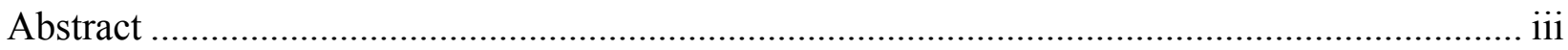

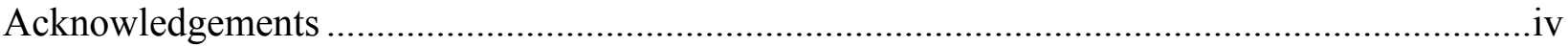

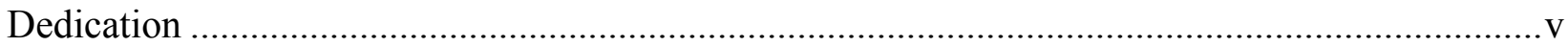

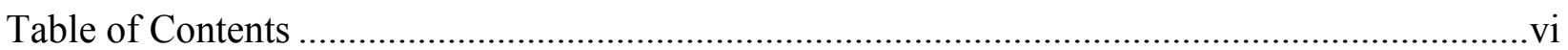

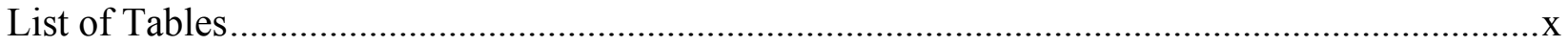

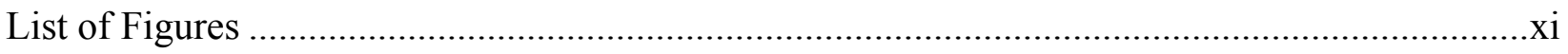

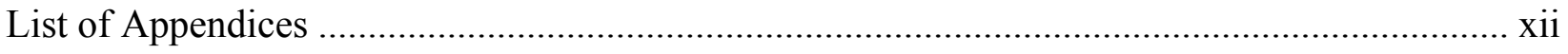

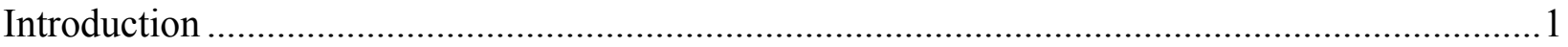

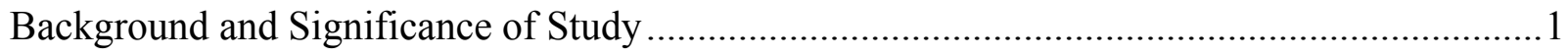

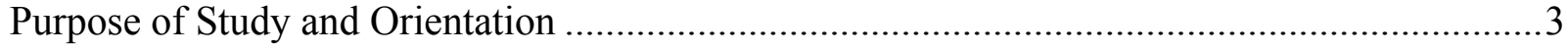

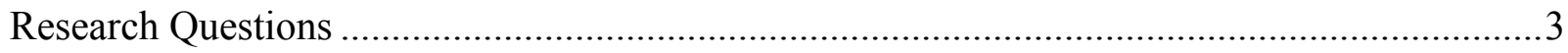

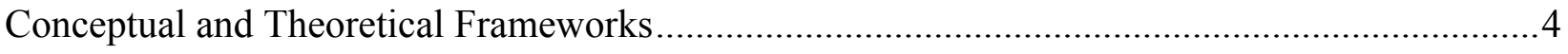

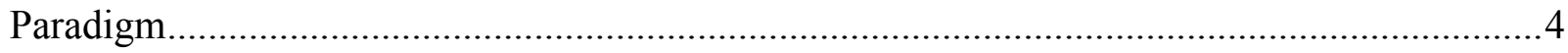

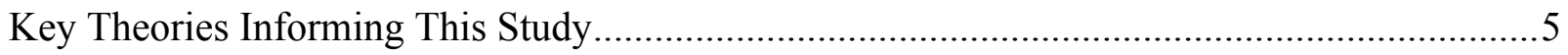

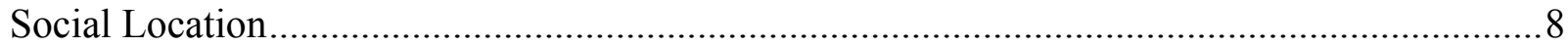

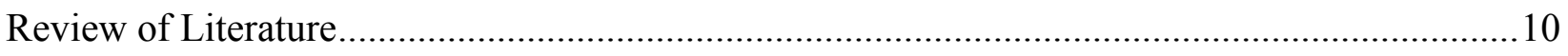

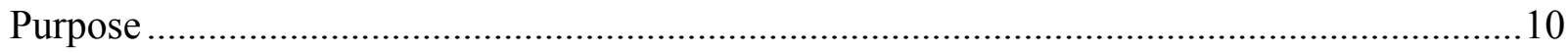

A Brief Historical overview of Approaches to Education ............................................... 10

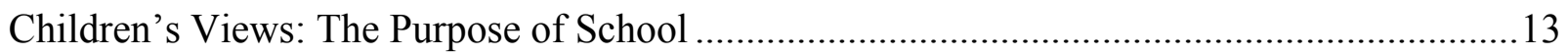


Children's Views: Work and Play in School .................................................................. 15

Children's Views: Friendship and Peer Relationships ................................................. 16

Children's Views: the Role of Teachers and of Teacher-Child Relationships .......................17

Children's Perceptions of their Agency in Educational Settings .......................................... 18

Children's Views of their Influence on Curriculum..........................................................20

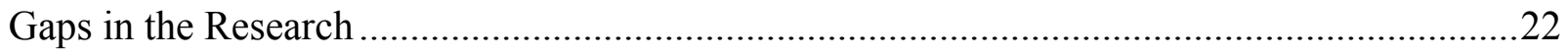

Conclusions Gleaned from the Review of Literature ........................................................23

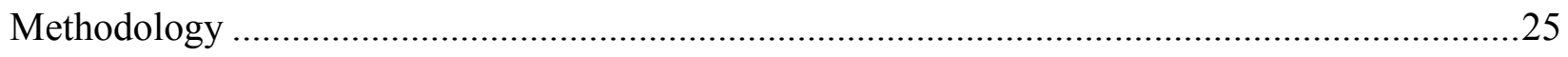

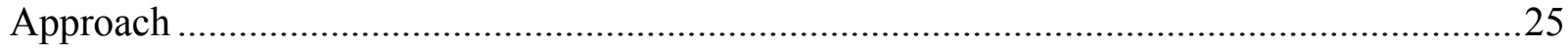

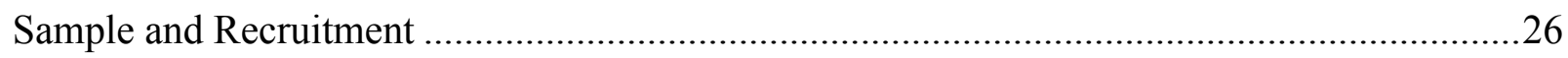

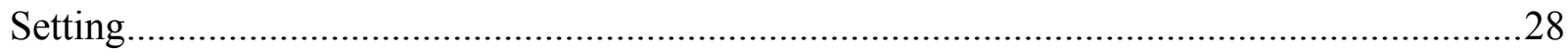

Data Collection Tools and Processes ..............................................................................29

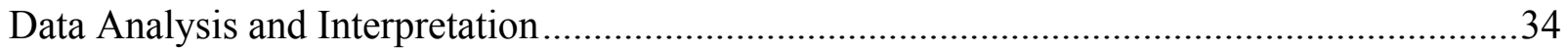

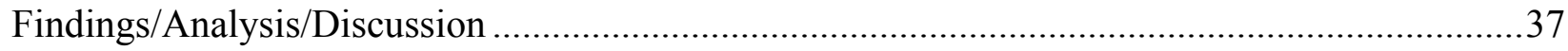

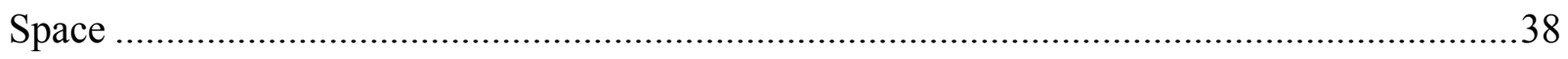

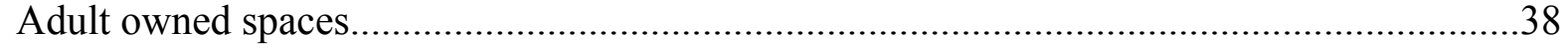

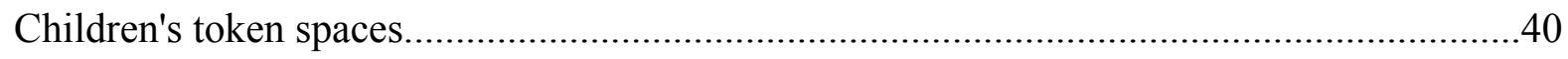

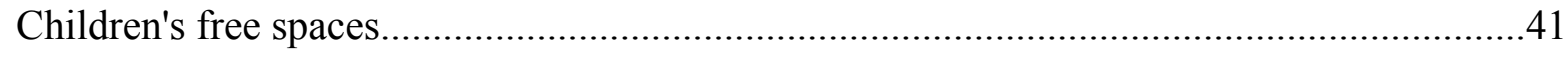

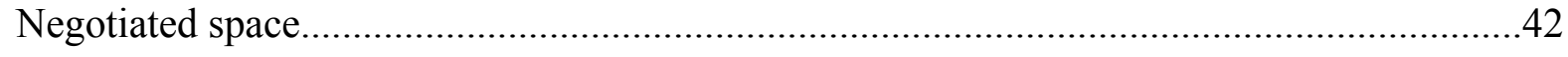

Space: Comparing learning environments........................................................... 44

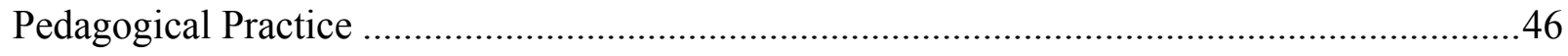

Children's preferred and prevalent school activities...................................................46

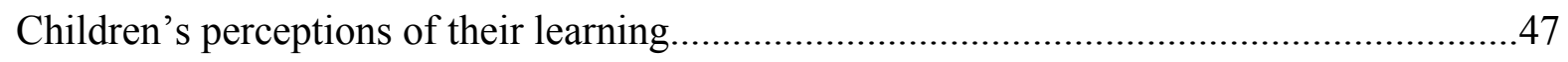




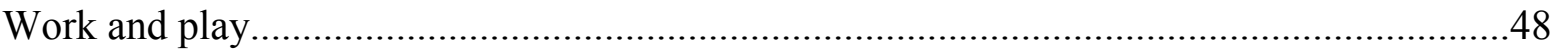

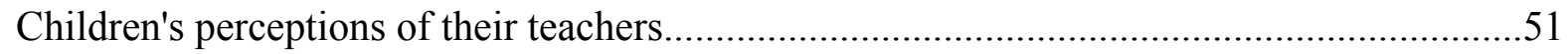

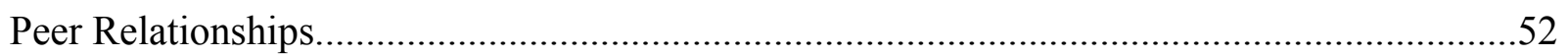

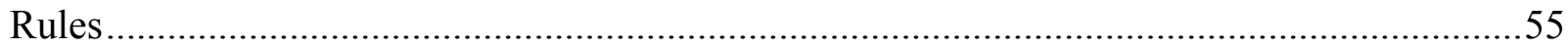

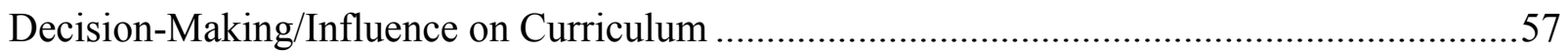

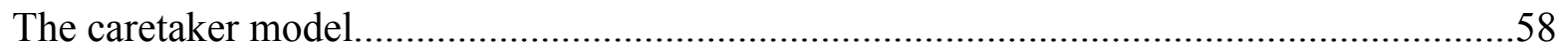

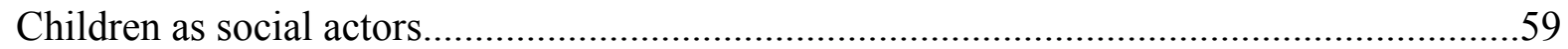

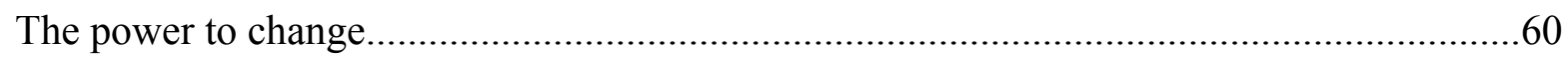

Summary: Implicit and Explicit Comparisons Between Learning Environments......................61

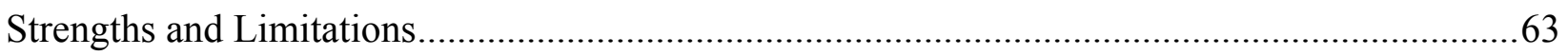

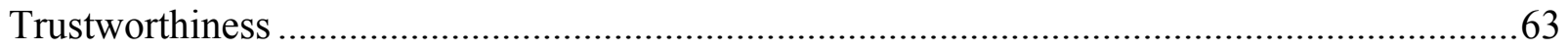

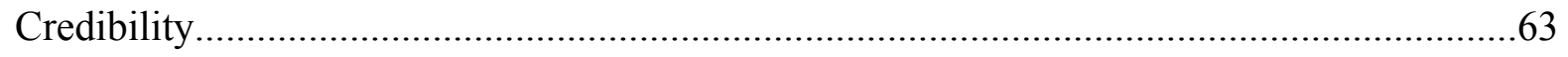

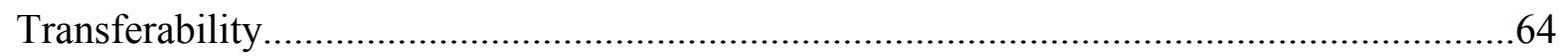

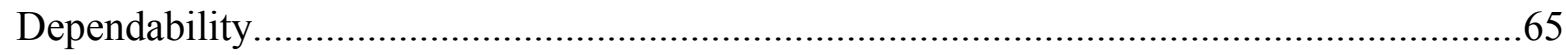

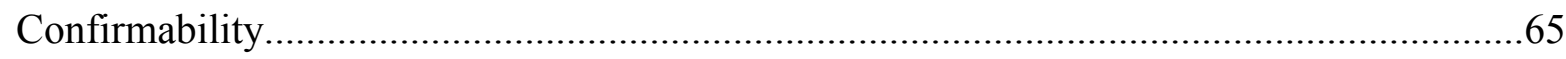

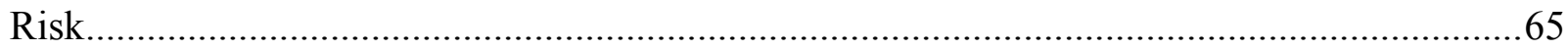

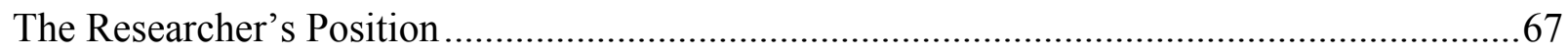

Reflecting on the Data Collection Process ..........................................................................68

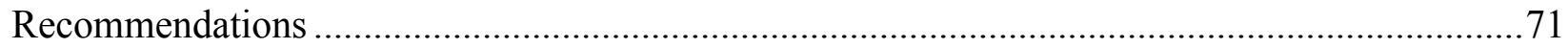

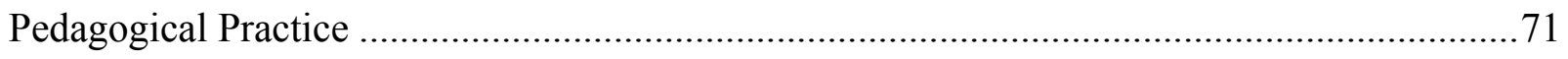

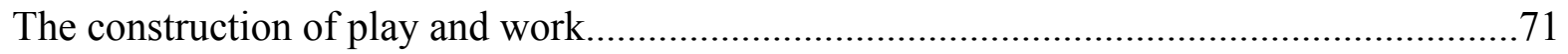

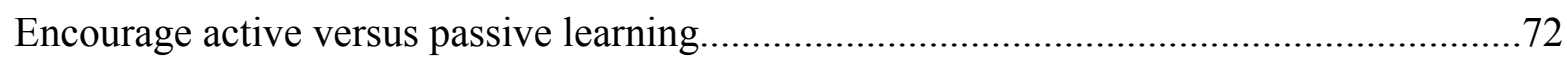

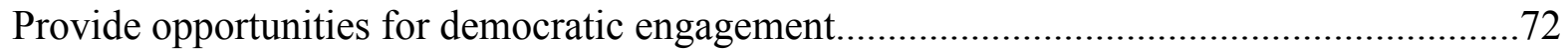




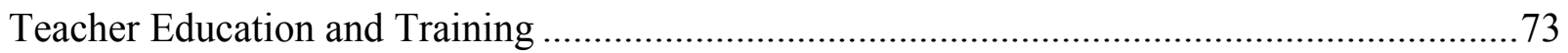

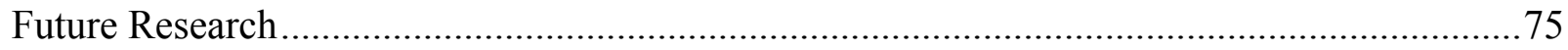

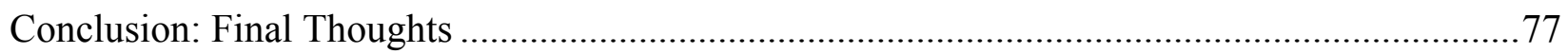

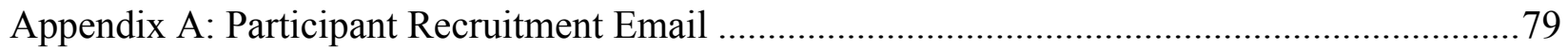

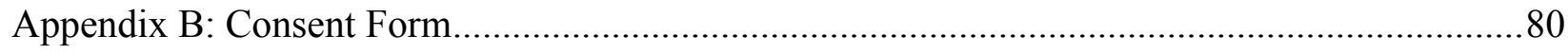

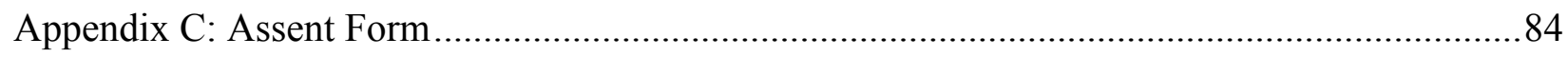

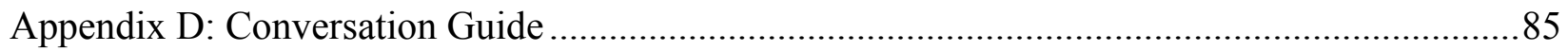

Appendix E: Photographs of the University Laboratory School..............................................87

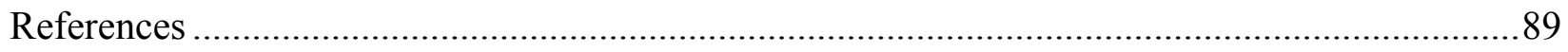




\section{List of Tables}

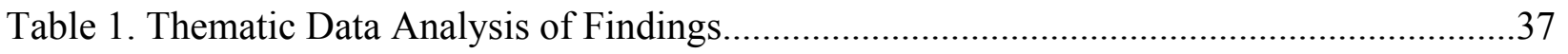




\section{List of Figures}

Figure1: Hannah's drawing of her current classroom.........................................................44

Figure 2: Ethan's drawing of his current classroom.........................................................44

Figure 3: Emily's drawing of her current classroom............................................................44

Figure 4: Ethan's drawing of the university laboratory school...........................................50

Figure 5: Hannah's drawing of the university laboratory school............................................55

Figure 6: Emily's drawing of the university laboratory school...............................................55

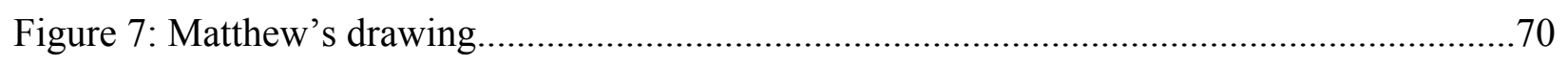




\section{List of Appendices}

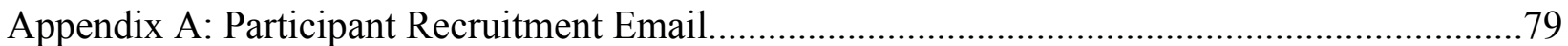

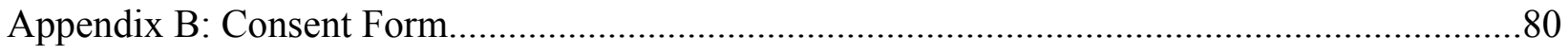

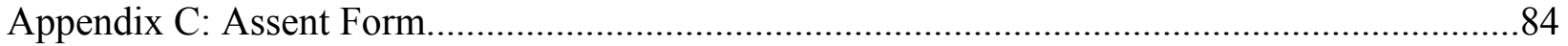

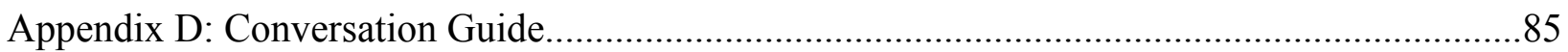

Appendix E: Photographs of the University Laboratory School.............................................87 


\section{Introduction}

\section{Background and Significance of Study}

When planning services and implementing policy for a specific adult population, such as support or health services, the particular group in question is generally consulted regarding how such services might best work for them, and in fact, failure to do so would likely produce questions of legitimacy and worth (Catt \& Murphy, 2003). This, however, is not typically the practice when planning services for children, at least in Canada, and more specifically in Ontario. This is in contrast to some countries around the world where children's opinions have become a point of consideration in recent years, for example in Australia (Dockett \& Perry, 1999; 2005a; 2005b), Iceland (Einarsdottir, 2008; 2010), and the United Kingdom (Glazzard, 2012; Singal \& Swann, 2009). In Ontario, however, when planning and implementing pedagogical practice, the perceptions of children are often unheard, or disregarded. Adults, drawing from adult experiences and perspectives, decide what is considered 'best' for children. Devine (2002) notes that educational experiences are "something 'done to' the children, legitimized by a discourse that prioritizes adult/future-oriented needs and expectations over present lived experiences” (p. 312). Dockett and Perry (2005b) acknowledge the perspectives of children vary from those of adults, and adults often have a narrow comprehension of children's perceptions and experiences. All too often, children's voices are dismissed as being immature, non-significant or unreliable, even when relating to issues directly concerning them, such as their learning environments. How children are conceptualised within a society influences to what extent their voices are heard and acknowledged.

The notion of 'childhood,' as separate from 'adulthood', emerged from middle class Europe between the fifteenth and nineteenth centuries (Ariès, 1962; Gillespie, 2012). From these two distinct conceptualisations, Gillespie (2012) argues that four key notions of childhood 
emerged; dependence, protection, segregation and delayed responsibility. This conceptualisation of childhood constructs children as separate from, and dependent on adults, in need of protection and unable to contribute to society in meaningful ways. This modernist construction of childhood and children influences many practices in early childhood studies and education, as children are regarded as separate beings relying on adult guidance in order to achieve individual independence. Within this construction, children are viewed as 'becomings' on a trajectory to adulthood, rather than as authorities on their own 'being' (Qvortrup, 2004).

While there are exceptions (Erikson, Gary, Wesley \& Dunagan, 2012; McBride \& Baumgartner, 2006; McBride \& Hicks, 1998), few published studies examine the perceptions of adults who experience laboratory school environments. Moreover, completely absent from the literature is information on how children perceive laboratory schools, generated by the children themselves. I believe this is a gap in the research that requires attention. Drawing from findings of a pilot study (Barnikis, 2013), where I interviewed two teachers from a university laboratory school, it is evident that, according to these teachers, children often face challenges adjusting to another school system after attending a laboratory school program. I believe this pilot study not only acknowledges some qualities unique to the university laboratory school, but also acknowledges that the two educational systems are not seamlessly aligned. These opinions, however, are second-hand, as they reflect the opinions of the teachers and may not best represent the experiences of the children themselves.

I believe a qualitative inquiry into children's perceptions of their past experiences in a laboratory school and in their current public school setting, will not only serve to highlight aspects unique to each pedagogical setting, but will also seek to understand children's experiences first-hand, and give a voice to group, particularly in Canadian society, which often goes unheard (Grover, 2004). Thus this study is scholarly and socially significant, as it will 
provide information on children's experiences and, therefore, generate new knowledge on how children reflect on different learning environments, and may initiate discussions as to how to better support children in their learning.

\section{Purpose of Study and Orientation}

The purpose of this qualitative study is to explore a small group $(n=5)$ of children's perspectives of their experiences in a university laboratory school and compare these with their experiences in a public elementary school setting. By interviewing children directly, I will cogenerate data on this subject with the children themselves. Throughout the research study, drawing from the 'new' sociology of childhood (Mayall, 2002; Prout \& James, 1997; Qvortrup, 2004), I aim to provide children with an opportunity to express their opinions and experiences on their learning. By doing so, I wish to acknowledge children as competent experts on their lived experiences (Dockett \& Perry, 2005b), and give a voice to a group that has been scarce in

published literature. Using the 'new' sociology of childhood as a theoretical framework (see below) this study will build upon current research exploring children's perspectives of their learning environments, however, it will generate innovative knowledge as the children will discuss and compare their experiences of two educational settings.

\section{Research Questions}

The research questions that I will explore are as follows: What are children's perceptions about their past experiences in a university laboratory school, and about their experiences in their current learning environment? How do children compare these experiences, directly and indirectly? 


\section{Conceptual and Theoretical Frameworks}

It is critical for a researcher to be transparent about their conceptual and theoretical frameworks as “all research emanates from the researcher's implicit or explicit theory of the phenomenon under investigation" (Rocco \& Plakhotnik, 2009, p. 121). Ravitch and Riggan, (2012) define conceptual frameworks as "an argument about why the topic one wishes to study matters, and why the means proposed to study it are appropriate and rigorous" (p. xiii). A conceptual framework, or research paradigm, is a guide to how the topic will be approached. A theoretical framework is "any empirical or quasi-empirical theory of social and/or psychological processes ... that can be applied to the understanding of phenomena" (Anfara, 2008, p. 3). A theoretical framework is a lens through which to explore a topic. I will begin by outlining the research paradigm of this project. I will then discuss the guiding key theoretical frameworks and my social location within this research study.

\section{Paradigm}

Throughout this research project, I will be working within a constructivist paradigm. Within this paradigm, humans are said to search for understanding of the world around them (Creswell, 2014). Previous to the 1970s, most educational researchers worked within a positivist paradigm, a paradigm which seeks to uncover universals, and which views knowledge as "being essentially discovered rather than something researchers construct” (Donmoyer, 2006, p. 17). During this research process, I am not seeking to identify a universal truth, as my study is grounded in the individual experiences of children in two educational settings. A constructivist paradigm is appropriate for the purposes of this research, as it allows for a comprehensive exploration into human behaviour that recognizes both disparities and similarities (Basit, 2010). I argue the constructivist paradigm honours my research purpose, as it is appropriate for researchers "who tend to relish nuances, appreciate differences, embrace ambiguity, and seek 
uniqueness in contextualized lived experiences" (Kumar, 2012, p. 800). I further assert that such an approach is reflective of my research questions, as I wish to explore the multiple experiences of children in laboratory school settings and compare these experiences to those which they are experiencing in their current learning environments.

\section{Key Theories Informing This Study}

As I am seeking to explore the children's opinions of their experiences in laboratory schools and how they compare these experiences with their current school setting, it is important for me to openly analyze my conceptualization of children. My views of children align with those of the 'new' sociology of childhood and the United Nations Convention on the Rights of the Child.

The 'new' sociology of childhood seeks to establish children as active participants in their lives, in the lives of others, and in the world around them (Matthews, 2007; Mayall, 2002; Prout \& James, 1997). Within this framework, children are recognized as having agency. Humans not only construct their knowledge through social interaction, but also through human action that involves agency. This is reflected in my research purpose, which seeks to recognise children as competent experts with agency.

Kincheloe (2002) states, the "vision of a desirable politics of childhood helps children articulate their own agendas and construct their own cultural experiences and facilitates their understanding of the complex dynamics that shape their relationships and interactions with adults and the adult word" (p. 39). By listening to children and valuing the ways in which they perceive the world around them, I wish to move past objectifying children in research, to acknowledging them as competent experts in their own ideas and experiences. This is why my research seeks to explore how children experience schools first-hand, from the children themselves, thereby honouring and acknowledging their experiences and their insights. 
The 'new' sociology of childhood rejects the notion that children experience childhood universally. This aligns well with the constructivist paradigm that drives my study, as the 'new' sociology of childhood framework seeks to establish "a variety of childhoods rather than a single and universal phenomenon" (James \& Prout, 1997, p. 8). In addition, my study seeks to explore the experiences of children in educational settings, and does not seek to generalize these experiences as universal of all children in such settings, but rather to focus on "local and specific constructed realities" (Lincoln \& Guba, 2003, p. 253).

A child rights-based perspective, drawing from the United Nations Convention on the Rights of the Child (1989), also underpins this study. The Convention on the Rights of the Child (CRC) recognises children as citizens who have distinct human rights, and who should be respected as active members in their communities. Articles 12 and 13 of the CRC explicitly state children have the right to be consulted on matters affecting them. These Articles further maintain children have a right not only to voice their opinion but to have these views heard, as Noyes (2005) indicates, "voices are nothing without hearers" (p. 536).

Although many nations have ratified the treaty, including Canada in 1991, children of these nations often do not have a voice in creating and establishing practices and policies that have a great impact on their lives. Glazzard (2012) notes the listening and acting upon children's perceptions about learning "demands a cultural shift in schools from a position whereby pupils are viewed as recipients of education to a position whereby pupils are viewed as partners in the processes of teaching and learning” (p. 60). Omitting children's perspectives when planning and implementing pedagogical practices works in opposition to the 'new' sociology of childhood's notion of children as active social actors, and the CRC's mandate of the right of children to express their opinions and to have these views heard. 
As this study explores children's perceptions of their experiences within the institution of school, critical theory also serves as a theoretical framework throughout this research project. Critical theory strives to "probe beneath the surface" of systemic practices which perpetuate "observable phenomena" thereby helping individuals to understand them (Sears \& Cairns, 2010, p. 48). Instead of viewing marginalised populations as "a minority of outsiders," critical theory illustrates how "large groups of people are constructed as inadequate or disabled through their circumstances" (Penn, 2008, p. 30). It acknowledges that problems in society do not happen in isolation but occur as the result of interactions between individuals and societal structures (Barakett \& Cleghorn, 2008).

This theoretical framework aligns with the 'new' sociology of childhood's view of children as marginalised in adult-dominated society (Mayall, 2002), where many aspects of children's lives are regulated and restricted by adults (Punch 2002). Children's everyday lives are experienced through social encounters, not only with their peers, but also with adults "who control institutions that justify and support the type of dependency that children experience" (Matthews, 2007, p. 327). Developed from critical theory, critical pedagogy explores the relationship between power and knowledge, and recognizes that knowledge is socially constructed and is deeply influenced by power structures (Barakett \& Cleghorn, 2008). Critical pedagogy questions the way in which knowledge is constructed, and challenges educational settings where the teacher owns, controls and transfers knowledge to children (Burke, 2005).

Milner (2013) urges society to "unpack, shed light on, problematize, disrupt, and analyze how systems of oppression, marginalization, racism, inequity, hegemony, and discrimination are pervasively present and ingrained in the fabric of policies, practices, institutions, and systems in education" (p. 1). Critical theory challenges, "how the status quo maintains inequality" (Schneider, 2003, p. 90), and moves away from examining and focusing on the individual, to 
investigating the larger system in which the individual is a part. Critical theory is a way of thinking and a method of critique (Barakett \& Cleghorn, 2008), which can be employed to challenge familiar everyday values and practices, instead of perpetuating power imbalances of the dominant normative views and practices within school systems.

Critical theory and the 'new' sociology of childhood together with the child rights-based perspective set out by the United Nations (1989) Convention on the Rights of the Child, underpins all stages of this research, and above all aims to recognise "children's position as actual citizens rather than as potential citizens in the making" (Devine, 2002, p. 317) while exploring children's perceptions of their experiences in different learning environments.

\section{Social Location}

Graue and Walsh (1998) state, "researcher perspective situates work in quite particular ways" (p. 74), as it draws from personal experiences and values. It is important that I reflect on my social location, as it will shape the lens through which I approach all stages of this research study. The laboratory school is a model of education that resonates well with me. I attended a university laboratory school as a child, and desiring a similar early learning environment for my son, I enrolled him in the same school. I also currently work at the same university laboratory school. As a former student, current parent and staff member, I believe university laboratory schools provide exemplary care and learning experiences for children while generating new knowledge in the field of childhood studies through research. I believe, due to their association with a university, laboratory schools provide children with opportunities not available in other education models by the provision of quality programming, a commitment to teacher training and a valued relationship of research to practice. It is these personal values and beliefs, which are driving my research project, and which led me to my research questions. 
My past experiences shape the lens through which I will collect and analyze my data, and it is important for me to be aware of this perspective, as well as to be transparent of my conceptual framework. Reason (1988) refers to this notion as critical subjectivity, "in which we do not suppress our primary experiences; nor do we allow ourselves to be swept away and overwhelmed by it; rather we raise it to consciousness and use it as part of the inquiry process" (p. 12). My past experiences and current values and subjectivity on university laboratory schools, serve not as biases, as when properly acknowledged, they serve to add further insight to my research purpose. 


\section{Review of Literature}

\section{Purpose}

The purpose of this review is to examine relevant literature related to the topic of the perceptions of children about their experiences in learning environments. This review will outline the history of some different approaches to education, as well as examine studies on the experiences and perceptions of children in different pedagogical settings. I will identify gaps in the available literature in order to provide a clear direction for my research, which will prove to be of both academic and social interest.

\section{A Brief Historical overview of Approaches to Education}

When examining aspects of current educational environments, it is imperative to examine the historical context of educational institutions. Barbour (2003) states that this examination leads us to more fully comprehend current practices, dilemmas, and possible solutions, and allows us "a way to grasp a better understanding of what we currently know and believe and to better understand the context in which we know and believe it" (p. 10). In order to understand current pedagogical practices and the perceptions of children about these practices, it is important to closely examine influential approaches to education.

During the late 1800 s and early 1900s, programs were established with the expressed goal of improving children's well being (Barbour, 2003). In particular, it was during this time that John Dewey began writing about his ideas and views of education, which led to the establishment of the University of Chicago Laboratory School, child development as a field of study, as well as to the Progressive Education movement.

John Dewey operated the Laboratory School at the University of Chicago from 1894 to 1904. It was one of the first laboratory schools in the United States, and during this time, Dewey wrote The School and Society. In this work, Dewey (1900) expresses his view on the current state 
of education and his desire for child education to be child-centred and experiential. He critiques "old education" and "its passivity of attitude, its mechanical massing of children, its uniformity of curriculum and method" (Dewey, 1900, p. 51). Dewey questions traditional curriculum and instruction methods, which he views as "isolation from life" (p. 89) where school is "only a place to learn lessons having an abstract and remote reference to some possible living to be done in the future" (p. 32). Dewey calls for a shift in pedagogical thought, from the school being in the centre of educational philosophies to the child being at the centre. He calls for an educational reform, based on experiential learning, which connects education with everyday life, and whereby the "isolation of studies as well as of parts of the school system disappears" (p. 106). Although Dewey wrote The School and Society over a hundred and ten years ago, his writings are still applicable and relevant today.

Dewey's (1916) Democracy and Education explores the role of education in creating democratic citizens. He argues that schools ought to demonstrate and foster democratic values, and that the schools should allow children the opportunity to experience the democratic process in reality, relevant to their lives. Dewey acknowledges the role of the teacher in planning the classroom curriculum, however, he maintains that children should have influence over their own education, by contributing their own experience and interests.

Along with Dewey, Lawrence K. Frank was central to the growth of child development laboratory programs (Barbour, 2003). Frank worked for the Laura Spelman Rockefeller Memorial, which between 1917 and 1927 initiated five child study sites across the United States. Through these programs, a three-part mission statement of service, training, and research was established for laboratory schools. This three-part mission is still employed by university laboratory schools today, and "serves as the cornerstone for the majority of such programs and guides many of their services and activities" (McBride \& Hicks, 1998, p. 21). Indeed, Barbour 
(2003) argues, the strength of a laboratory school lies in how well it can balance the three-part mission, but simultaneously acknowledges that schools must be responsive to their individual communities. Similarly, McBride et al., (2012) acknowledge that each laboratory school develops from its own context.

If we move ahead a number of years to the end of the twentieth century, we encounter another influential educator and philosopher, Paulo Freire from Brazil, who not unlike Dewey, critiques traditional educational practices. Freire (2000) compares such pedagogical practices to those of the financial sector, referring to them as the "banking concept" of education; students were simply viewed by most as empty bank accounts in which teachers 'deposited' information. He criticizes such an approach to education as one directional in which the teacher is in charge, and bestows the learning, or information, onto the child, and calls for an educational system, which encourages critical thinking and bidirectional dialogue between children and educators. Freire (2000) believes that children and teachers should both be involved in the production of knowledge by drawing from their unique experiences and backgrounds.

Freire's philosophy of education is echoed in American psychologist Barbara Rogoff's (1990; 2003) notion of guided participation. Within the concept of guided participation, knowledge is said to occur as children learn and participate through observation in everyday activities with the support of adults who "provide suggestions and responsive - rather than directive - assistance" (Rogoff, 2003, p. 302). The learning results from a mutual contribution of adult and child opposed to the social influence perspective, "which attributes socialization to adults who organise children's learning" (Rogoff, 2003, p. 285).

Finally, U.K. historian and educator Peter Moss (2007), similar to Dewey, maintains pedagogical settings should be places of democratic political practice. He expresses the importance of democratic participation in school stating, "it is a means by which children and 
adults can participate with others in shaping decisions affecting themselves, groups of which they are members, and the wider society" (Moss, 2007, p. 7). Moss asserts that there are two models of early childhood education, 'the market model' and 'the model of democratic practice'. Within the market model, education produces pre-determined outcomes similar to a factory, and offers (sells) a commodity to parents as consumers reflecting a business institution. The model of democratic practice offers opportunities for all its members to participate in decision-making, evaluate practices, question dominant discourses, and have the ability to change practices (Moss, 2007). This model is based on reciprocal and mutual relationships and dialogue between citizens, adults and children alike. Published literature on children's perceptions of their experience in learning environments, drawing from different educational approaches, will now be further explored.

\section{Children's Views: The Purpose of School}

Einarsdottir (2010) interviews six and seven-year-old children to elicit their perceptions about their experiences of their first year of primary school. The majority of the children view learning reading, writing and mathematics as the main focus of primary school. This is similar to the result of Devine's (2002) study, in which she interviews and observes children between the ages of seven and eleven in order to gain information on their perceptions of children and childhood in present day Ireland. The children identify learning, which they classify as work, as the primary purpose of their school experience. These studies (Einarsdottir, 2010; Devine, 2002) appear to reflect Moss' (2007) market model and Freire's (2000) banking model of education, whereby predetermined outcomes are produced as the teacher (the provider) bestows knowledge (the commodity) on the student (the purchaser) (Einarsdottir, 2010).

Singal and Swann (2009) examine children's views of themselves as learners both inside and outside the school setting. The study found that learning outside the formal school 
environment is located within the children, however learning and knowledge within schools appears to be located within the teacher, as in these settings, knowledge is characterised by children's dependence on teachers. Listening to the teacher embodies the learning that takes place within a school classroom setting. This again reflects the banking model of education as the teacher owns and controls the knowledge, and is the sole transmitter of knowledge. The children perceive this learning inside the classroom as different to their learning outside the classroom where there is a greater emphasis on learning through observation rather than listening. This learning is more reflective of Rogoff's guided participation, in which the learning is bidirectional.

Singal and Swann (2009) report that when children discuss learning inside of school, they do not view the learning as relevant to their current lives. Rather, they view this learning as pertinent to them in the future, when they transition into becoming an adult. This appears to reflect dominant societal views of childhood as a preparation for adulthood, where children are viewed as 'becoming' rather than 'being,' (Qvortrup, 2004) and where assuring future success for children underpins the purpose of curriculum, and builds upon Dewey's critique of education from over a hundred years ago.

In an earlier study by Einarsdottir (2008), she utilises various techniques including group interviews, photography, drawing and games, in order to elicit children's and parents' views of the purpose of playschool in Iceland. The study explores the perspectives of twenty-two children between the ages of five years of age and six years of age of their playschool, which for the context of the study, refers to all group care services of children between the ages of eighteen months and six years of age. The children from this study, view the main purpose of playschool as place to go while their parents are working. Although factors such as what parents tell their children about why they go to playschool may play a role, this result may imply the playschool 
places less of an emphasis on academic achievement and preparation than the school of Singal and Swann's (2009) study.

\section{Children's Views: Work and Play in School}

Einarsdottir (2008) finds playschool children place a high importance on play and selfinitiated activities. When children are asked what they liked to do most at playschool, most of them respond with play activities, however, when the children are asked what they like least about their learning environment, they answer most often with activities which they are not able to control themselves such as, sitting still and following adult instruction. These results echo Einarsdottir's subsequent study, which reports most children maintain they like school most when they can choose what to do, however, what children most often mention as being boring or difficult at school is reading, writing and mathematics lessons. Einarsdottir (2010) finds when discussing their educational experiences, children distinguish between the notions of 'work' and 'play'. The children classify work as "obligatory and decided by the teacher" and play activities as "initiated by themselves" (Einarsdottir, 2010, p. 177). These results appear to reflect an earlier study by King's (1979), which reports that children distinguish play activities from work activities, by defining them as both voluntary and self-directed. King (1979) also finds teachers use of the words 'play' and 'work' mirrors the children's understanding of the terms.

In some of the previously examined studies, there appears to be a correlation between whether children view their classroom activities as work or play, and their enjoyment of the classroom activities. Ceglowski and Bacigalupa (2007) interview pre-school children who predominately describe their daily activities at childcare as play, whereas Singal and Swann (2009) find children, aged nine to eleven years, view learning at school as work. These children report feeling disconnected from their learning and feel it holds little relevance to their wider 
world. They, however, do not classify their learning outside of school as work even when this learning is viewed as difficult or challenging for the children.

When discussing what is effective curriculum, Glazzard (2012) finds children in his study view 'good' lessons as those in which the children's interests are reflected. Many of the participating children, who are between seven and eleven years of age, acknowledge they are engaged by learning experiences that are "interesting and purposeful" (Glazzard, 2012, p. 58), and where students can be active participants in their learning.

\section{Children's Views: Friendship and Peer Relationships}

Friendship and peer relationships are themes that are prominent throughout the literature on children's perceptions of their experience in educational settings. Einarsdottir (2010) finds that when children are asked to take picture of what they like most about school, the often take photographs of friends. Singal and Swann (2009) report children place a great emphasis on the importance of friends at school. One child from the study states, "I like school because I have my friends" (Singal \& Swann, 2009, p. 6). Similarly, when Ceglowski and Bacigalupa (2007) ask children ranging in age from one to eighteen years of age to describe childcare experiences through interviews and drawing, the children most often respond that one of the 'best' aspects of childcare is being able to play with their friends. Many of the children draw pictures of doing a favourite activity with a friend. These findings are similar to those of Dockett and Perry (1999) who state making friends at school is of great importance to young children. Devine (2002) recognises the importance of friendship and "child culture" to children, particularly when navigating their subordinate position in school and the power imbalances in adult-child relationships. Indeed, when asked what would they miss when they left the playschool, Einarsdottir (2008) maintains that most children respond with social relationships with other 
children, however, they also note their relationships with staff; this relationship will now be discussed further.

\section{Children's Views: the Role of Teachers and of Teacher-Child Relationships}

Einarsdottir (2010) reports children perceive that the main role of teachers is to teach children reading, writing and mathematics, and to ensure that assignments are completed correctly. Some of the children mention that the teacher is "the one who ruled and they have to obey" (Einarsdottir, 2010, p. 175). Within the classroom setting, the children in Einarsdottir's (2010) study identify themselves as powerless, with the teacher controlling the power of the classroom. Devine (2002) also notes that children's descriptions of their interactions with teachers are underpinned with notions of subordination, and that children perceive themselves as having an inferior status within the school setting. These children are aware of, and articulate of, their position at the bottom of the social hierarchy of the school. Not only do these children view teachers as authoritarian, "directing and constraining children in the activities which they could pursue" (Devine, 2002, p. 313), they acknowledged that teachers do not always listen to them or take their concerns seriously due to their subordinate status as children.

Devine (2002), drawing from Foucault's (1979) work on institutions where he discusses the role of institutions such as schools in promoting and reproducing dominant and normative discourses of power, suggests the structuration of adult-child relations in society is reflected in how children experience school. Thus, children's everyday lives are experienced through social encounters not only with their peers, but also with adults. As within the banking model critiqued by Freire, Burke (2005) notes, there is an underlying "assumption that prevails within a school environment that knowledge is owned, controlled and transferred to others by adults" (p. 31), and children are often not acknowledged as being capable of holding expert knowledge (Dockett \& Perry, 2005b). 
Dockett and Perry's (2005a; 2005b) Starting School Project aimed to report on children's lives as they start formal school. Findings from the Starting School Research Project report children often mention classroom and school rules as being important for children to know before starting school. Dockett and Perry (1999) state that children's awareness of rules serves to indicate their understanding of the hierarchical nature of school.

Glazzard (2012) interviews children between the ages of seven and eleven about their perceptions of their education including their views of teachers, curriculum, assessment and school inspection. The children identify a 'good' teacher as being fair as well as being strict, and one who makes lessons interesting. Conversely, the children identify 'bad' teachers, as those who did not listen to children and do not speak to children in a respectful manner. The study finds that children believe they have a right to be listened to and that their opinions should be acknowledged as equally valid as the views of their teachers, however theses view often go unheard in educational settings. The following section will further examine children's views of their agency within their learning environments.

\section{Children's Perceptions of their Agency in Educational Settings}

Drawing from modernist constructions of childhood, dominant Euro-American society conceptualises childhood as a waiting ground in which children acquire the necessary skills in order to become adults. In this dichotomous relationship, the adult holds the power. Within this perception of childhood, children are thought to have little, or no agency. Sears and Cairns (2010) define human agency as, "the ability of humans to act upon the world in order to achieve a goal" (p. 185), further it is, "the degree to which individuals have control over their own behaviour and actions" (Cheah \& Chirkov, 2008, p. 403). Within a modernist construction of childhood, children are not viewed as capable, or competent in making their own decisions, or acting upon them. 
Devine (2002) maintains children are positioned as subordinate within the school environment, and acknowledges historical "discourses related to deviance, dysfunction and deficit as well as innocence and vulnerability have dominated adult images of children, precluding and consideration of children as social actors with a voice of their own” (p. 305). Devine (2002) and Glazzard (2012) examine whether children believe they have any influence over what they do during the school day. Glazzard (2012) finds that children believe they have an influence in matters involving classroom environment, lunchtime, and the playground, however, the children do not mention being consulted in matters regarding curriculum, teaching or assessment. Devine (2002) reports that although children do not feel they have an influence on these areas of the school day, they would like to be given more opportunity for consultation especially concerning structuring the school timetable, creating greater flexibility in daily routine, and being able to choose and influence activities and curriculum.

Some of the relevant literature examines children's agency in educational settings, not only in terms of being able to influence their school day, but also how this influence affects their satisfaction of, and engagement with, school. Einarsdottir (2010) finds children believe they can decide what to do at recess and during free time, however they do not feel they have any influence on school curriculum. The study finds most children mention free time, recess and playing as they most enjoyable parts of school. Einarsdottir (2010) concludes, "it can therefore be assumed that if the children had some choice in or influence on the programme, in some of them would have preferred other emphases" (p. 176). Einarsdottir (2010) maintains children have little chance to practice democracy. It is worth noting this situation is in direct opposition to the pedagogical recommendations put forth by Dewey (1916) and Moss (2007). Devine (2002) further highlights the importance of practicing democracy when stating "children's identification of themselves as citizens is influenced by the discourses concerning children and childhood 
which govern their world" (p. 305). It is incongruous that a society, which expects full engagement of its citizens, through democratic processes, does not often listen to its children until they reach the age of majority. How can humans feel their opinions are valid if they are not listened to until an arbitrary day, when society deems them worthy?

As previously discussed, the 'new' sociology of childhood argues for the recognition of children's agency, as it rejects the modernist conceptualisation of the passive child, and views children "as active in the construction and determination of their own social lives, the lives of those around them and of the societies in which they live" (Prout \& James, 1997, p. 8). Drawing from the 'new' sociology of childhood, Dockett and Perry $(1999 ; 2005 a ; 2005 b)$ also examine children's experience in schools, and through their research process they aim to support children's agency and possible influence over school programs. An encouraging aspect of the Starting School Research Project is that the study demonstrates that data generated from research with children can be used to influence school practice and programs. Through the project, children create books illustrating their perceptions of their experiences starting school. These books, created by the children, are being used to inform current transition practices at their school in Australia.

\section{Children's Views of their Influence on Curriculum}

Sheridan and Samuelsson (2001) interview thirty-nine five-year old children from six preschools in Sweden in order to explore the children's perceptions of decision-making in their learning environments and their opportunities to influence curriculum. External evaluators classified three of the pre-schools as being of 'low quality' and three as being of 'good quality.' The majority of the children when asked what they who choose to do at school, if given the opportunity, respond with 'play'. Sheridan and Samuelsson (2001) ask the children if they 
believe their teachers know what children like to do. Eight-two percent of children from the highquality preschools maintain that the teacher do, or maybe know what children prefer to do, while in the low-quality pre-schools forty-five percent of children believe their teachers do not know what they like to do.

Sheridan and Samuelsson (2001) find children's concept of decision-making falls into two categories; 'to decide' involves children making choices by themselves or with friends, alternatively, 'to allow' or 'to forbid' is concerned with the decision-making of the teacher. The majority of the children confirm that the teacher is the one who most often makes the decision in preschool. The teacher makes the decisions involving curriculum, routines, rules, as well as the overall norms and values of the classroom. Children often find that the teachers override their desire to do something. Children recognise that they do make decisions regarding play and what to do during playtime, but not when playtime occurs for example, one child states, "I decide what to paint, but not when" (Sheridan \& Samuelsson, 2001, p. 184).

Rosen (2010) interviews thirty-four children and three teachers from one preschool in Canada. It is important to note that this preschool was purposefully selected for the study as teachers of this preschool, Rosen included, actively strive to incorporate children in curriculum development. The approach to education within this preschool is "Reggio-inspired," influenced by the practices of the Reggio Emilia approach in which children are central to the development of curriculum (Rosen, 2010). Rosen finds children's perceptions of curriculum development is classified into three categories; who has the idea, who decides if the idea should be implement, and how the idea is realised. In contrast to Glazzard's (2012) study, most children within Rosen's classroom believe that their ideas do influence curriculum, however, the children make a distinction between having an idea and making the final decision as to whether the idea will be implemented. Amongst the children of Rosen's (2010) study, there is a consensus that it is the 
teacher who makes the final decision. The children maintain that they enjoy being able to influence the curriculum, however, echoing the findings of Devine (2002), the children of Rosen's (2010) study wish they could have a greater influence on curriculum.

\section{Gaps in the Research}

As I reviewed this literature, I identified gaps in the published research. The aforementioned studies are limited in their context as few available studies on the perceptions of children about their experiences of their learning environments are from Canada (Rosen, 2010 and also Di Santo \& Berman, 2012 are exceptions). I believe, especially with the roll out of fullday kindergarten in Ontario, it would be beneficial to study current perceptions of children regarding their experiences in pedagogical environments within a Canadian, and even provincial context.

Dockett and Perry (2005b) acknowledge children's perspectives vary from those of adults, and adults often have a narrow comprehension of children's perceptions and experiences. While reporting on the views of children, many of the aforementioned studies include adult perceptions, including teachers and parents, along side those of the children, for example, Devine, 2002; Einarsdottir, 2008; Singal \& Swann, 2009. Although not always contradictory, I believe the inclusion of adult perceptions works to decrease the validity of the children's voices as their perceptions are often only validated through adult voices. Children's views should be explored in their own right and not only in conjunction with adult voices. This is a hindrance to the research, as how can one begin to fully understand the experiences of children in pedagogical settings if these views are being compared to, or validated by adult perceptions? I believe children's perceptions do not need to be justified or validated by the experiences or opinions of adults. 
Noyes (2005) states it is imperative that schools be aware of which voices are listened to and which are privileged. Dockett, Einarsdottir and Perry (2009) acknowledge that in research with children, gatekeepers often select certain children to participate; therefore the same voices are continuously represented. Many of the aforementioned studies examine the perceptions of older school-age children. Glazzard (2012) maintains that when selecting participants for the study, the school purposefully omitted younger children. Thus, the school's leadership team did not allow the youngest children to participate in the study. Glazzard (2012) notes that the chosen children were "confident, able and articulate" (p. 61). By speaking with younger children, those who have just started school, this inquiry will give a voice to a group, which is often absent from the reviewed literature, thereby providing innovative research to the field of early childhood studies.

\section{Conclusions Gleaned from the Review of Literature}

Matthews (2007) maintains the 'new' sociology of childhood challenges the approach to research in which adults speak for children and their experiences, thereby privileging adult voices, and subsequently silencing children's voices. Working within this framework, and by listening to children and valuing the ways in which they perceive the world around them, I wish to move past objectifying children, to acknowledging them as competent experts on their own lived experiences. This is why my research seeks to explore how children experienced their laboratory school, and experience the current school program in which they are enrolled, from the children themselves, thereby honouring and valuing their experiences and their insights. As noted above, few studies explore children's perceptions of their experiences in educational setting, solely from the child's perspective, without the inclusion of a 'validating' adult voice, fewer studies still, examine the perceptions of young children, and fewer still take place within a Canadian context. This review of literature further affirms the relevance and significance of my 
expressed purpose of study and my research questions of: What are children's perceptions about their past experiences in a university laboratory school and about their experiences in their current learning environment? How do children compare these experiences directly and indirectly? 


\section{Methodology}

\section{Approach}

I employ a qualitative approach to this research project. The rationale for a qualitative approach is that such an approach seeks to examine individuals' experiences and opinions (Creswell, 2014). This is in opposition to a a quantitative approach which "assumes that clear cause and effect relationships can be established while scrutinizing human behavior" (Basit, 2010, p. 15), which, I believe, can lead to a generalization of perceptions and does not seek to explore the individuals' experiences and opinions. Within a qualitative approach, however, "the social world has no objective existence independent of individuals' views, perceptions and behaviour" (Basit, 2010, p. 16). Within a qualitative approach, the researcher aims to construct meaning from the perspectives of the participants (Creswell, 2014). A qualitative approach reflects my choice of a constructivist paradigm, as I wish to explore human experiences and perceptions. I believe, with a qualitative approach, the individual opinions and experiences of the children will be explored in more depth, allowing for a more detailed and nuanced study.

It is important to acknowledge my position as an adult in co-constructing the conversations with the children, and in framing, analyzing and interpreting the data. Dockett and Perry (2005a) question how adult researchers can “faithfully represent children's knowing and understanding" (p. 518). When conducting research with children, despite involving children in the data collection, the analysis and interpretation of the data often does "demand different knowledge than that generally available to children, in order to explicate children's social status and structural positioning" (Mayall, 1994, p. 11). This is consistent with research involving adults where researchers also analyze and discuss their findings through the access to academic theories, concepts and knowledge (Punch, 2002). For this research project, however, during the data analysis, and during all stages, I need to be mindful of my position as an adult researcher, 
and of children's marginalized position in society, in order to help ensure that the findings and analysis best represent the children's perceptions of their experiences.

\section{Sample and Recruitment}

My sample included five children who have transitioned from a university laboratory school kindergarten program to a public school setting within the last eight to ten months. I anticipated this would have allowed for the children to adjust to their new educational setting, while also still being able to remember many aspects of the laboratory school setting. The participants had completed the 2012-2013 school year at the same university laboratory school, however, are currently enrolled at different public schools. Two of the children are enrolled at the same public school, but are in different classes. Three of the five children are enrolled in the Ontario's full-day kindergarten program. One child is in a half-day kindergarten program at a school, which will transition into the full-day program in three months. One child is enrolled in grade one at a school. I sought to include a mix of genders in my study as I wish to acknowledge the experiences of both genders.

In order to gain access to the participants, after receiving approval for this study from the Ryerson Research Ethics Board, I approached the manager of the university laboratory school, and ask her to send an introductory email (see Appendix A) to the parents of children who had recently transitioned from the laboratory school to the public school system. I provided the manager with a brief outline as to the purpose of my research study and ask her to inquire, by email, if any parents would be interested in participating in my study. As I am familiar with some of these parents, I did not want my existing relationship with the children and their families to place any pressure on their decision to partake or not to partake in my study. The introductory emails distributed by the manager of the laboratory school, helped to ensure that my pre-existing relationship did not affect the voluntary participation of the individuals in my study. It was left to 
the families wishing to participate in my research study to contact me directly. On the consent and assent forms I used, I made it unequivocally clear that participation in this research project was entirely voluntary, and that the children and their families may choose to leave the study at anytime.

The sample selection was purposeful as only families of children who had experienced the kindergarten program at the university laboratory school, and who left the school during the summer of 2013 were sent the introductory email. The manager of the university laboratory school sent an introductory email to sixteen families and six families responded to me directly that they would like their children to participate in the study. I sent the six interested families the consent form (see Appendix B) and arranged a time to meet with the participating children. Unfortunately just prior to an arranged meeting one child was admitted to hospital and withdrew from the study. In the end, five children, two girls and three boys, between the ages of 4 year and eleven months and six years and nine months of age participated in the research study. Assent forms (Appendix C) were distributed to the participants, and incorporated into the data collection process, which will be discussed in further detail in following sections. The assent and consent forms both acknowledged my intention of protecting the confidentiality of my participants. In order to help ensure the confidentiality of the children in this research project, throughout the discussion of findings and following sections, all names have been replaced by pseudonyms.

My choice to focus on children, and not interview adults (families or teachers) is a purposeful one. Referring back to my theoretical framework of the 'new' sociology of childhood, I wish to honour the ideas and experiences of children, and not justify their responses through an adult voice. Through this study, I wish to establish children not as unformed and unreliable, but rather as competent "social agents" who can challenge and make a difference to "a relationship, a decision, to the workings of a set of social assumptions or constraints" (Mayall, 2002, p. 21). I 
believe this agency does not need to be justified or validated by the experiences or opinions of adults.

\section{Setting}

The data collection took place in the homes of the children outside of school hours. The choice to speak with children at their homes and not at their school was a purposeful one. Mayall (2008) acknowledges that methodologically the home and the school both present different challenges to the data collection process. Although the school space is a familiar space to children, it is a space that is controlled by adults, and one in which children are positioned as dependent on adults (Matthews, 2007). Children are conditioned to behave a certain way in a school environment, and this setting may promote the idea of right or wrong answers. Burke (2005) notes, in a school setting children may respond in a format in which they believe is expected of them in that setting. Thus, I purposefully chose not to collect data in a school setting as I am exploring children's perceptions of their learning environments, and I did not want to the power imbalance present in these settings to influence the children's discussions.

Collecting the research data in the children's home was not only convenient for my participants and their families, it also provided the children with a setting in which they may consider familiar and comfortable (Spratling, Coke \& Minick, 2012). Conducting research in the children's homes did, however, create some challenges. As I was a guest in the children and their family's home, as Mayall (2008) notes, my social position did not "have clearly established parameters; it [had] to be negotiated" (p. 116). Mayall (2008) speaks of the "triangle of conventions and negotiations" (p. 116), which is present when employing the home as a research site with children. The data collection needed to be negotiated with the parent, and with the child, as well as between the child and the parent. This presented a challenge to my research project in terms of whether the parent would be present during the data collection. The issues of where in 
the home to conduct the research, and who was present during the process were addressed at the beginning of each home visit. Parental presence is an important factor to consider during data collection with children, as parents who are present can be comforting to children, but may also have an influence on what children say (Spratling et al., 2012). For this research project, the choice of whether the parent remained with the child during the data collection was handed over to the child. I spoke with four children without their parent's immediate presence, and one child requested that his parent remain throughout the data collection process.

\section{Data Collection Tools and Processes}

Punch (2002) explores the question of whether research methods with children should be different than research methods with adults. Drawing from the 'new' sociology of childhood, Punch acknowledges that children are marginalised in an adult-dominated world, and that often children are so acclimatized to this power imbalance that they are accustomed to adults not regarding them as equals. Punch (2002) states, "perceiving children as competent social actors does not necessarily mean that research should be conducted in the same way as with adults" ( $p$. 338). In other words, when conducting research with children, it is imperative that researchers are cognisant of children's marginalised position in society, and establish research methods that aim to diminish, or at least recognise, the power imbalance between child participant and adult researcher. This approach to selecting data collection tools reflects my working within the 'new' sociology of childhood. I do not believe that research methods need to be adjusted because children are inherently different or less competent than adults. I do, however, believe that when conducting research with children, researchers may adjust methods to reflect children's marginalization in an adult dominated society.

Research with children strives for “an acceptance that children's knowledge of their own worlds is owned by them and that they are the experts in knowing and recording their own 
worlds" (Burke, 2005). This research goal not only reflects my conceptualisation of children, but it also echoes my working within a constructivist paradigm. In order to support this objective, I refer to Punch (2002), who maintains when conducting research with children it is imperative that researchers remain reflective during all stages of the research project, and "critically reflect not only on their role and their assumptions, but also on the choice of their methods and their application" (p. 323).

Within a qualitative method, the researcher is the one who physically collects the data (Creswell, 2014). I engaged in conversations with the children in order to collect the data for my research project. Mayall (2008) refers to engaging children in conversations where "an opening gambit could lead wherever children wished" (p. 112). A conversational approach, I believe, is conducive with working within a constructivist paradigm where the views and experiences of the participants help guide the study (Creswell, 2014). Dockett et al. (2009) also refer to conversations as a method to elicit children's perspectives of their learning experiences. I wish to make it explicitly clear that my use of the term 'conversation' instead of 'interview' is not because I believe that children are not competent in interview situations, rather it reflects my view of children's marginalized position in society, and my desire to establish a data collection environment which is responsive to the power imbalance which exists between children and adults.

Conversations with children about their experiences in different learning environments can be viewed as a form of oral history. Oral history is a methodological tool that has been traditionally employed by historians to generate data about peoples lived experiences (Haynes, 2010). Oral history allows for the exploration of memory, perception and feelings of a lived experience, and has the "potential of opening up new areas of inquiry or exposing the voices of those marginalized" (Haynes, 2010, p. 221). The oral histories of children, however, are not 
traditionally explored. If children are to be recognized as competent informants on their lived experience, then their oral histories should be explored and valued.

I created a semi-structured conversation guide (see Appendix D), which provided the children with broad areas of discussion. From these open-ended questions, the children guided the conversations by discussing points that were of interest to them, and I followed up on the development of these ideas as they emerged throughout the conversation. Within this data collection tool, my role as researcher was "of facilitator and enabler who encourages the research participant to 'speak their mind' on issues" (Roberts-Holmes, 2010, p. 109). In my guide, I included probes to help progress the conversations, and to further aid in ensuring the comfort of my participants.

Spratling et al. (2012) state "establishing a connection with the child during the interview [is] critical to successful research outcomes" (p. 48). I believe, a semi-structured format allows for rapport to develop between child and researcher, as the child can talk freely and guide the direction of the conversation, and allows "the child to talk about things that are important to them, not just what is important to the researcher" (Spratling et al., 2012, p. 52). I began the conversations by asking the children some introductory questions in order to help establish a connection with the children, and help to ease any anxiety the children may have been feeling. Cameron (2005) refers to this as a period of 'free narrative,' which serves a dual role in assisting the child in becoming more comfortable with the research process, and with allows the researcher time to assess the child's communication style and individual needs and concerns.

I engaged with the children in one-on-one, face-to-face conversations. I believe that speaking with the children one-on-one helps to assure the privacy and confidentiality of the participants. As well, face-to-face conversations added to the comfort level of the children, as I was able respond to their body language and facial cues, further building the rapport between the 
child and myself. In order to further increase the comfort level of the participants, I made it clear, through an assent form, that the children had the choice to participate in the data collection and could choose to stop participating in the research project at any time. When conducting research with, not on, children it is an important part of the research process to have children give their assent, or agreement to participate, prior to the data collection and to respect their wishes if they do not want to participate in, or continue with the research project (Dockett et al., 2009).

I utilized an audio-recorder during the conversations with the children, as it allows for active listening (Roberts-Holmes, 2010). By not physically writing down the words of the participants, I was able to more completely focus on the conversations, and their distinctive nuances and unique directions. This is especially important in a semi-structured format where the direction of the conversation was not entirely predetermined. Audio recording also enhanced my interactions with the participants during the data collection, as I was able to more easily engage with the participants using body language and eye contact, as well as being able to take notes on these non-verbal elements of the conversations. I acknowledge the presence of an audio-recorder may be intimidating to children who are not familiar with the device. In order to ease this possible anxiety, and to build further rapport with the participants, prior to the conversations, I presented the audio-recorder to the children and demonstrated how it worked, as well as answering any questions they may have had about it. At the beginning of each meeting the children pressed the record button to begin the recording process. I supplemented these notes with a field $\log$ where I recorded detailed notes on the context of each meeting.

During the conversations I asked the children to draw a map of their current classrooms as well as to draw a picture of what they remembered from their past classroom. Punch (2002) states that task-based methods, such as drawing, may enable children to feel more at ease with the data collection process, but it is critical that the researcher remains reflective and does not choose to 
employ such methods because they believe they are more enjoyable for children, but because they can also produce meaningful and useful data. Drawings are "rich visual illustrations which directly show how children see the world" (Punch, 2002, p. 331). As I have not visited the children's current classrooms, their drawings helped me visualise their current space as well as serving to highlight areas of the classrooms that the children thought to be important and which they wanted to discuss. By asking the children to also to draw a picture of their own classroom, information was generated not only on how they remembered their past classrooms, but also on how they compared the two learning environments.

More specifically, during the drawing process, I asked the children to describe to me what they were drawing. These conversations went past a description of the physical representation of their drawings to exploring their perspectives of their learning environments. Within this method, the drawing became "a constructivist process of thinking in action, rather than developing ability to make visual references to objects in the world" (Cox, 2005, p. 123). What the children were saying while drawing was as important as what they were drawing, and neither can be analyzed separate from the other. This method aligns well with a constructivist approach and helps to ensure that the interpretation of the drawing lies with the child participant and not with the adult researcher (Dockett and Perry, 2005a).

Drawing provides children, who may have challenges expressing themselves verbally, a means of expression. Drawings and can aid children in expressing their lived experiences as well as "the unrecognized, unacknowledged or 'unsayable' stories that they hold" (Leitch, 2008, p. 37). Einarsdottir, Dockett and Perry (2009) maintain that children may feel more comfortable as they do not need to maintain eye contact with the researcher, and they are engaged in an activity that is familiar to them. Punch (2002) maintains that drawings, which are fluid and can be altered and added to, allow children the time and control to form what they wish to convey. 
It is important to note that Punch (2002) cautions researchers not to assume that drawing is a "simple, 'natural' method to use with children" (p. 331), as this data collection tool depends on children's comfort of, and their actual ability to draw. One child from this study refused to draw, and an additional child stated that he did not know how to draw his classroom. It is interesting to note, however, the child who maintained he did not know how to draw his classroom, did want to draw the blocks in his classroom, and continued to draw throughout my speaking with him, this may illustrate the aforementioned benefits of task-based methods.

I provided the children with photographs of their past kindergarten classroom at the university laboratory school (see Appendix E). Most of the children had not been in this classroom for over eight months, and so these photographs were used to stimulate conversations about the children's perceptions of their experiences in the classroom.

Through the selection of data collection tools and processes, I aimed to reflect my conceptualisation of children as competent experts on their own lived experiences and to maintain a balance between not patronising children while establishing their agencies and competencies. I aim to answer my research questions by facilitating a means for my participants to express and communicate their perceptions of their experiences in different learning environments.

\section{Data Analysis and Interpretation}

To begin my data analysis, I transcribed the recorded conversations. Although time consuming, the transcribing, word for word, provides a further level of analysis that is challenging to obtain from written notes (Roberts-Holmes, 2010). Once I had a typed document of each transcript, I read over each transcript, and listened to the voice recordings, multiple times in order to become familiar with the data. I incorporated the drawings into this stage of analysis by studying them alongside the transcripts and the recordings. I engaged in a thematic network 
analysis of my data. Within a qualitative approach, researchers "build their patterns, categories and themes from the bottom up by organizing the data into increasingly more abstract units of information" (Creswell, 2014, p. 186). After becoming familiar with my data, and by analyzing each line of the transcripts alongside the drawings, I began to identify themes throughout the data. I allocated each of these themes a colour and marked relevant sections of the transcripts using the thematic colours. I continued to review the transcripts, adjusting and collapsing themes, and created a codebook to briefly describe the various codes. Throughout this process, I established connections among my codes, allowing me to identify major and minor themes throughout my data.

Interlacing my reviewed literature, my research questions, and my conceptual framework with my data, I identified relationships among my codes. Graue and Walsh (1998) state in qualitative research, a researcher "must draw from everywhere - other theories, one's own and others' insights, and empirical insights" (p. 28). Drawing from the themes and the relationship among codes, I created drafts of my analyzed themes, which I further refined. In order to help readers make sense of my research, I referred back to my research questions in order to support claims of the knowledge and theories generated by my study (Mukherji \& Albon, 2010). This will hopefully bring all information together for readers, as well as identifying implications for practice, theory or future research.

Lincoln and Guba (2003) state that in qualitative research issues of validity, or trustworthiness, arise around "the conflation between method and interpretation" (p. 274). While addressing validity in my study, I drew from the rich data of detailed verbatim transcripts, identified any discrepant and contradictory data throughout my analysis, and allowed "other messages to be 'heard', messages that were not answers to the questions that were being asked" (Stephenson, 2009, p. 137). I acknowledge the possible differing experiences and opinions of my 
participants, and not only focus on the data that fits nicely together, as exploring conflicting data enhances the credibility of a qualitative study (Creswell, 2014). I am cognisant that I need to be continually transparent of my conceptual framework through all stages of the research process. 


\section{Findings/Analysis/Discussion}

In the data generated from the conversations with the children, and from their drawings, I identify several key aspects of the children's perceptions of their experiences in different learning environments. In the analysis that follows, the overarching theme of power and hierarchy is prominent throughout the children's descriptions of their experiences. More specifically, I have located the theme of power and hierarchical structures in the children's discussions and descriptions of: space, pedagogical practice, peer relationships, rules, and decision-making and influence on curriculum (see Table 1).

\begin{tabular}{|c|c|c|}
\hline $\begin{array}{l}\text { Overarching } \\
\text { Theme }\end{array}$ & Secondary Headings & Tertiary Headings \\
\hline \multirow{14}{*}{$\begin{array}{l}\text { Power and } \\
\text { Hierarchy }\end{array}$} & \multirow{5}{*}{ Space } & Adult Owned Space \\
\hline & & Children's Token Spaces \\
\hline & & Children's Free Spaces \\
\hline & & Negotiated Spaces \\
\hline & & $\begin{array}{l}\text { Space: Comparing learning } \\
\text { environments }\end{array}$ \\
\hline & \multirow{4}{*}{ Pedagogical Practice } & $\begin{array}{l}\text { Children's Preferred and Prevalent } \\
\text { Classroom Activities }\end{array}$ \\
\hline & & $\begin{array}{l}\text { Children's Perceptions of Their } \\
\text { Learning }\end{array}$ \\
\hline & & Work and play \\
\hline & & $\begin{array}{l}\text { Children's Perceptions of Their } \\
\text { Teachers }\end{array}$ \\
\hline & Peer Relationships & \\
\hline & Rules & \\
\hline & \multirow{3}{*}{$\begin{array}{l}\text { Decision-making and } \\
\text { Influence on Curriculum }\end{array}$} & The Caretaker Model \\
\hline & & Children as Social Actors \\
\hline & & The Power to Change \\
\hline
\end{tabular}

Table1: Thematic Data Analysis of Findings 


\section{Space}

Space, and how it is used and designated within a learning environment, can illustrate freedom or the lack of it. Cole (2009) states, "adults structure public spaces in ways that marginalize children" (p. 23). Through their conversations and their drawings, the children discuss teacher spaces, children spaces and spaces which are negotiated by both teacher and child. Throughout these conversations, issues of power imbalance, hierarchical structures and children's marginalisation are explored.

Adult owned spaces. When speaking about their current classrooms, Ethan, Matthew and Emily make direct references to teacher-owned spaces within their classrooms. The children discuss the teachers' desks, chairs, and separate rooms. When drawing his current classroom, Ethan states that he is going “to make her [the teacher's] chair right here. I am going to make it giant," and he places the chair next to his teacher's "big screen." Ethan's description and drawing of the teacher's property as large, in relation to the other classroom elements, may illustrate a power imbalance between his teacher and the children in the classroom. The scale assigned to the teacher's property may denote a sense of importance, which is missing from the other elements of the classroom. It is possible to infer that Ethan draws his teacher's property larger, as she is physically larger then the children, however, I believe Ethan's following descriptions of the teacher's separate room, validates the interpretation of power over the interpretation size.

When drawing his current classroom, Ethan also refers to "Madame's room," which is off the main classroom. The room is separated from the classroom by a fence, thereby inhibiting the children from entering the space. This is a clear division between teacher and child space. Within this classroom, the teacher has created a space of her own, which is forbidden to the children. This perpetuates a power imbalance between the teacher and children in the classroom, as the teacher has additional space that the children are aware they cannot enter. There is even a 
physical barricade, constructed by the teacher, to control who has access to the space. In summary, although the space is physically part of their classroom, it is not accessible to all members of the room.

In his discussion, Matthew also makes reference to an adult owned space. He states that when children are in "big trouble" they go to the office "because there's a principal in our school." He comments on the location of this space being "not in the classroom, it's downstairs on the first floor." It appears that the teachers and principal have constructed the office as a place that students should fear, as it is a place where children who do not follow the rules and expectations of the classroom go as a punishment. Within this construction, the presence of the office and the principal can be viewed as a means of maintaining control and governing through fear. The threat of having to go to the office for disrupting the rules of the classroom is a means in which the teacher upholds the rules of the classroom. The occurrence of children being singled out in class, and being sent to the office, appears to have had an impact on Matthew, as he can recall the names of children in his class who have been to the principal's office; "Robert and Lucy and Sam are also sometimes silly, but they have been to the office before that means they are in big trouble". This finding in consistent with those of Docket and Perry's (1999) study, which recognises children's awareness of the hieratical nature of the school context. Through these descriptions, Matthew appears to acknowledge the social standing of the principal, as higher than that of his teacher.

Through their conversations, the children seem to be aware of spaces in their current classrooms that belong to teachers. These spaces are identified and controlled by the teachers of the classrooms. The children also identify spaces that the teachers identify as 'belonging' to children. These spaces will be further explored in the following section. 
Children's token spaces. Through their conversations and drawings, the participants identify spaces in their classrooms, which appear to be child owned space, but which are, in reality, controlled by adults. Cole (2009) states, “children's spaces are limited by adult and societal influences" (p. 27). When discussing their current classrooms, Ethan and Emily refer to “our tables" and "our desks," however, these spaces, although identified as belonging to specific children, are controlled by the teachers. It is the teachers who decide what activities are done at these tables. Ethan states that when the children enter the classroom in the morning, "we sit at our tables, we read French books in our head." He further mentions that at their tables the children "do our note journals." Although the children refer to the tables and desks as their own, the teacher controls the activities performed in these spaces.

It is not only the activities that are controlled by adults in these spaces, but also which child uses which space. Ethan and Emily discuss how, in each of their classrooms, they sit at the same tables everyday. Emily maintains that the teacher selects where each child sits "so you don't talk to people." Thus, such spaces, which may be at first impression, identified as child owned areas within the classroom, are in reality illusory child owned spaces. Although through the use of possessive pronouns, they appear to 'belong' to the children, they offer a false sense of ownership, as they are in fact heavily controlled and limited by the teachers in the classrooms.

Matthews and Limb (1999) refer to "token spaces," areas such as playgrounds, which are perceived as child spaces. They further define tokenism in relation to space as "situations in which children seem to have a voice but in essence have no real say, choice or chance to formulate their own opinions or to influence outcomes" (Matthews \& Limb, 1999, p. 80). Although children are given their own spaces in the classroom, this appears to be tokenistic, as in reality these spaces are in fact regulated by the teacher. This further establishes the hierarchical 
structure of the classroom, as even spaces which are identified as 'belonging' to children, are in fact, controlled by adults.

Children's free spaces. Cole (2009) refers to "free-spaces" as areas in which children can establish their agency within the school landscape. They are often spaces that many adults view as insignificant, however, they are "critical, contested and empowering" spaces for children (Cole, 2009, p. 27). In their conversations, all the children make reference to washrooms, and or to snack and lunch tables. Olwig (2011) maintains that washrooms are often "special places," identified by children, as somewhere to congregate and to develop sociality.

When drawing his current classroom, Ethan begins by drawing where the bathroom is located, and then as he draws the classroom of the university laboratory school, Ethan tries to remember if the bathroom is located inside or outside the classroom. Typically, school washrooms are spaces that are free of, or have minimal, adult supervision. Three of the five children (Ethan, Matthew and Emily) make reference to washroom spaces. This may illustrate how important these spaces are to the children, and in turn, how important spaces free from adult control are to children. These results appear to support the findings of Dockett and Perry's Starting School Project (2005b), where they find that when identifying places in the school, children often photograph "taboo places" such as washrooms and other areas with limited teacher supervision.

In his conversation, Matthew comments on how during carpet time, only children who need to go to the washroom, or who need to get a drink may leave the carpet. Emily notes that during rest time children are also allowed to leave to use the washroom. Within these contexts, the washroom offers a permitted break from the classroom routine. It allows children the opportunity to step away, if only briefly, from the adult-dominated classroom. 
In their conversations about their experiences in their current classrooms, all of the children discuss snack and or lunch time. Olwig (2011) maintains that many children describe lunchtime as a highlight of their school day, as this time provides opportunities for social interaction and less adult control. Ethan notes that what he really likes about school is eating lunch and snack. He states, "what I really like... is eating lunch... yeah and snack.” Lunch tables, like with bathrooms, are spaces in which "children create and participate in their own unique peer cultures by creatively taking or appropriating information from the adult world to address their own peer concerns" (Corsaro, 2015, p. 18). In an environment controlled and limited by adults, children often use the opportunity that unmonitored spaces provide to demonstrate their agency and to socially negotiate with each other.

Through his conversation, Sebastian appears to recognise the duality of space. He describes the art table in his current classroom and notes, "but sometimes it's a lunch table." This appears to indicate, that at times the adults of the classroom may govern a space, and at other times the children may control the same space. It is the teacher, however, who decides when the tables are used for which purpose.

Negotiated spaces. The classroom carpet, and the activities which take place on the carpet, feature significantly in all discussions of the children's current classrooms. The carpet appears to be central to the routines of each of the classrooms. Hannah states "that's where we go for story time and other stuff like when its home time we have to go to the carpet when we are going somewhere we have to go to the carpet." Sebastian notes that the first thing the children in his class do in the morning is go to the carpet, as that is where "we learn about what we are doing for work today." The carpet also features in all three of the current classroom drawings. Figures 1,2 and 3 illustrate how the carpet appears to be an item of great significance in each of the children's drawings of their current learning environments. While drawing their current 
classrooms, the children spent a concidereable amount of time on the classroom carpets. In all three drawings, the carpet is the classroom feature that is given the most amount of detail. Hannah begins her drawing with the carpet and spends much time replicating the checkered pattern of the carpet. Ethan states that the classroom carpet is "like an oval except we call it big and round" and in his drawing he illustrates the letter pattern of the carpet. Emily describes the carpet in her classroom as a "world carpet" and in her drawing she shows the details of the different countries and the oceans.

Through the children's discussions and their drawings, it is evident that the carpet is a central space in the daily goings-on of their current classrooms. The activities the children engage with on the carpet, and the physical set up of the carpet time appear to further maintain the teacher as controlling the space, and the children as marginalised within the classroom environment. Ethan and Emily both mention that they have specific spaces on their classroom carpets, assigned by their teachers, on which they must sit. Ethan states, "squares are where we sit, Q is my letter.” As with the tables and desks, the teacher also controls where the children sit on the carpet. The children sit on the floor facing the teacher who sits elevated on her "big chair." This represents, in a visual manner, the hierarchical structure of the classroom, as the teacher is literally not at the level of the children, but is situated above them. The power of this image can be taken a step further to argue that the children sitting facing the elevated teacher serves to illustrate Freire's banking model of education. The learning here is one-directional whereby the elevated teacher is passing on knowledge to the children below. Through physical placement, and through teacher directed activities, the carpet further upholds the power imbalance and hierarchical structures of the classroom. 


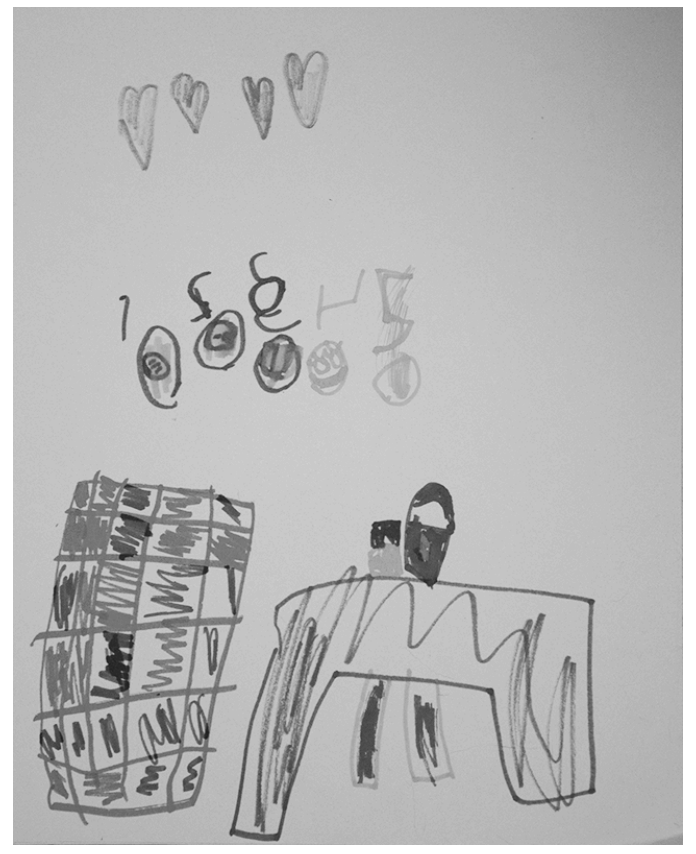

Figure 1: Hannah's drawing of her current classroom. The carpet can be seen on bottom left.

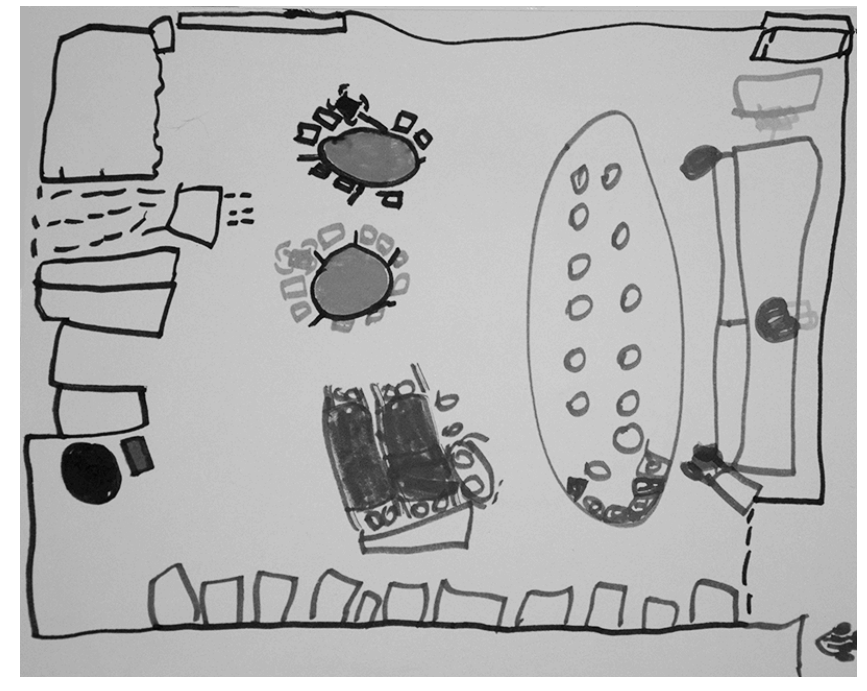

Figure 2: Ethan's drawing of his current classroom. The carpet can be seen at the right side of the page.

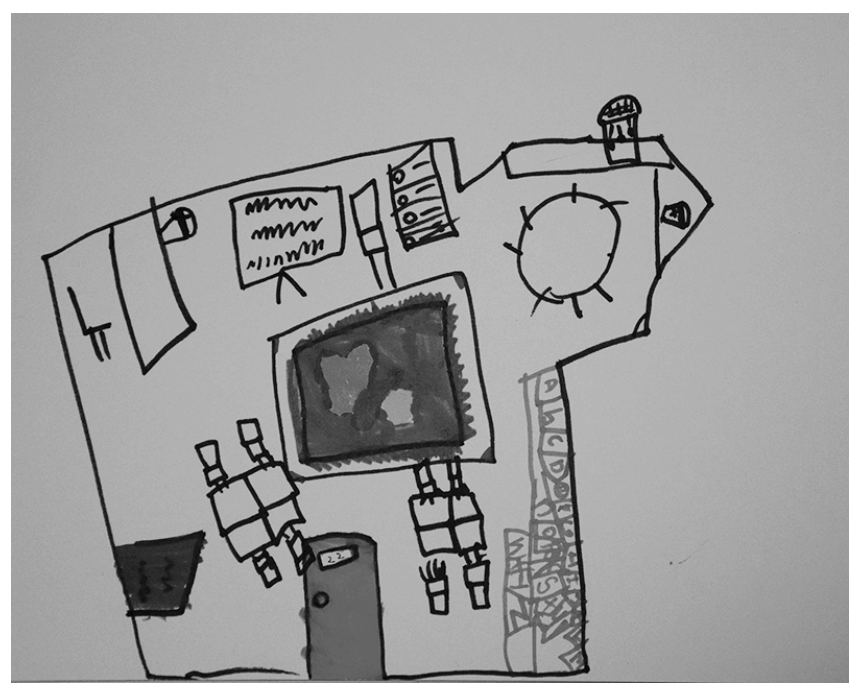

Figure 3: Emily's drawing of her current classroom. The carpet can be seen in centre of page.

Space: Comparing learning environments. When reflecting on their experiences in the kindergarten room at the university laboratory school, the children make no mention of teacher or child controlled spaces. Unlike their discussion of their current classrooms, the children did not 
refer to teachers' desks or chairs or to children's tables or desks. This may illustrate, that in this environment, there is no distinction made between teacher and child spaces. When reflecting on their experiences at the university laboratory school, the children did mention the carpet area, however, it is discussed as an element of the reading area, and is not given as much detail in the drawings. Ethan comments that the carpet in the kindergarten room of the university laboratory school is "nothing like the [current classroom's] one."

The theme of washrooms and lunch or snack time were present in both settings. When asked what some differences between the two classrooms are, Matthew responds "Well, in this class (current classroom) I have a washroom in it, and in this classroom (university laboratory school) there's not a washroom in the class." When drawing the early learning classroom, Ethan cannot remember if the washroom was inside or outside of the classroom. In the kindergarten room of the university laboratory school, the washroom is located in separate room, which is accessed through the cubby area, and is not directly attached to the classroom, which is in contrast to Matthew's and Ethan's current classrooms where the washrooms are connected directly to the room. The children's focus on the location of the washroom and how the location differed in the different education settings, may further illustrate the importance the children place on these 'free spaces'.

In Western nations, a larger proportion of children's daily activities occur in classrooms (Theobald, Danby \& Ailwood, 2011). Space communicates with people. Room arrangement and usage project messages about what is valued and expected in certain environments. Cole (2009) argues that adults organise space to further marginalise children. Within their current classrooms, the teachers appear to organise the classroom space in order to uphold the governing status of the teacher, and the subordinate status of the children. The conversations with the children identify many issues of power imbalances and hierarchical structures deriving from the organisation and 
management of the space of their classrooms. The children also recognise spaces, in which children might escape some of the control of adults; these spaces appear to be valued by children in each of the educational settings.

\section{Pedagogical Practice}

Children's preferred and prevalent school activities. When asked what they like about their learning environments, both past and current, most of the children refer to activities in which they are active. In the interviews the children make many references to enjoying building with blocks, engaging in art activities and playing in the playground. Hannah states she likes school "because I get to draw" and Ethan points to and area of his drawing of the university laboratory school and says, "this is the make centre and I love making stuff."

These findings appear to support the Ontario government's full-day kindergarten curriculum which provides full-day learning for all four and five year olds across the province, and aims to "establish a strong foundation for learning in the early years, and to do so in a safe and caring play-based environment that promotes the physical, social, emotional, and cognitive development of all children" (Ontario Ministry of Education, 2010, p. 1). As stated earlier, of the five children I spoke with, three children (Hannah, Ethan and Matthew) are currently enrolled in the full-day kindergarten program. Sebastian is enrolled in a half-day kindergarten program, which will be transitioning to the full-day program in three months. Emily is currently in grade one at a school that has the full-day kindergarten program implemented.

The Full-Day Early Learning-Kindergarten Program (draft version) is a curriculum document written by the Ontario Ministry of Education (2010) in order to outline curricular expectations of the full-day kindergarten program. Created for educators, the document contains descriptions of play-based learning, of the skills and knowledge children are expected to acquire, and of the anticipated roles of the classroom educators. The document acknowledges the 
importance of play as "a vehicle for learning and lies at the core of innovation and creativity" (p. 13). The children in this study identify play and active activities as their most favourite part of the school day. These finding appear to support Sheridan and Samuelsson's (2001) study which found that play was the activity most mentioned by children in response to what activity they would choose to do in their learning environment if they were the ones making the decision.

In discussing what they liked best about school there was no distinction made by the children between their current classrooms and the kindergarten classroom of the university laboratory school. There was, however, a distinction made between the different educational settings when the children discussed what they did in the day. Teacher directed activities dominate the conversations when the children discuss what they do in their current school classrooms. In these settings, children appear to make a distinction between what they like to do and the majority of classroom activities.

Children's perceptions of their learning. The children, when discussing the learning in their current classrooms, often describe one-directional learning in which the children listen to the teacher. When discussing how his teacher uses "her big screen" to teach the children, who are sitting on the carpet, Ethan states, "she makes us watch TV so that we can learn stuff. She thinks watching TV is how we learn except really it's not for me." He goes on to comment, "she thinks if we hear it one time we will really learn it except I need a bunch of times for my learning." These comments illustrate the banking approach to education, an approach that reinforces the hierarchical nature of the school. These statements also serve to highlight children as reflective and competent experts on their lived experiences. Ethan not only recognised the educational approach employed by his teacher, but he is aware that it is not conducive for his learning. This further illustrates the possible knowledge that can be gained in the field of pedagogical practices, 
if children, the ones who experience the educational system first had, are consulted and their views valued.

Thornberg (2010) notes that educators often ask children questions in order to evaluate their knowledge, not to provide them with "opportunities to think aloud, formulate ideas, make suggestions, or have a say" (p. 930). This is also reflective of the banking approach to education as children are viewed as passive and empty vessels that the teacher must fill with knowledge. When asked what the teacher does when the children are on the carpet Emily replies that she "just teaches us stuff" and the children "raise [their] hand when the teacher asks us a question." This appears to reinforce a conceptualisation of children as "objects, not subjects of learning receivers, not actors" (Cole, 2009, p. 25). In opposition to the 'new' sociology of childhood, within this construction children are not viewed as social actors, but rather, as passive recipients. Although the children identify that they enjoy learning activities that are active, it appears that passive teacher-directed learning dominates classroom activities in the children's current classrooms.

Work and play. The participants also make a distinction between 'work' and 'playtime'. Sebastian states that after the children sit on the carpet, "the second thing is doing our work and then the third thing is playing and then the forth thing is leaving." In this setting, work and play are separated, however, as many experts in the field of early learning argue, academic content and play are not dichotomous (Cooney, Gupton \& O'Laughlin, 2000; Goodman, 1994). Play can incorporate academic ideas. Indeed, the Full-Day Early Learning-Kindergarten Program (2010) curriculum document states, "play and academic work are not distinct categories for young children, and learning and doing are also inextricably linked for them" (p. 13). However, according to the children in this study, not only are the activities dichotomous, in their school settings there is a hierarchy amongst the activities. By playtime occurring at the end of day, it 
may be inferred that play is viewed as a reward for finishing work; an activity only allowed once the work is completed. By its placement in the schedule, the teacher directed 'learning' is given more importance over the child directed 'playtime' again reinforcing the hierarchical structure of the classroom.

Not only does the placement of play in the school day appear to reflect the hierarchical structure of the classroom, so does the time allocated to this activity. Emily states, "we only have playtime one time in the day" and that it is twenty minutes in duration. Matthew notes that outside time, a period defined by the child as 'playtime,' lasts fifteen minutes. The Full-Day Early Learning-Kindergarten Program (2010) curriculum document recommends, "providing large blocks of time for both child-initiated and structured play" (p.14). The time allocated to play as described by the children cannot be considered 'large'. The United Nations (1998), in Article 31 of $\mathrm{CRC}$, recognizes play as a specific right for all children, and yet children are experiencing limited play opportunities in school settings, environments in which they spend a large percentage of their daily lives.

Not only do the children in this study acknowledge their preference for active activities, when asked what she would change about her current classroom, Emily replies, that she would like "a playground in our classroom." This appears to indicate that Emily recognises that play is limited in her classroom, and that it is something of which she wishes there was more. This separation of 'work' and 'play' was not present in the children's reflections of their experiences at the university laboratory school. Through their discussions of this classroom, there was no mention of the word 'work.' When asked what he remembered doing in the early learning classroom, Matthew replies, "playing." Unlike their discussions of their current classrooms, active activities dominated the conversations of both what they liked doing, and what they did in this classroom. When drawing the early learning classroom, the children began by 
drawing the water table, the sandbox, the block centre, and the slide. This is in opposition to how they began their drawings of their current classroom, which began with the carpet, the teacher's room, the bathroom and the teacher's desk. Four of the five children discussed the classroom's sandbox and the system of bucket and pulleys above it. Ethan recalls the details of the sandbox in his drawing (see Figure 4). He states, "there's the wheel... and there's the ropes... a big wheel... a rope... then here the third one is." This classroom element is represented in two of the three early learning classroom drawings. This feature allows children the opportunity to explore and actively learn through experimentation, and through its prominence in the conversations and in the drawings of the children, it can be assumed it is a valued component of the classroom.

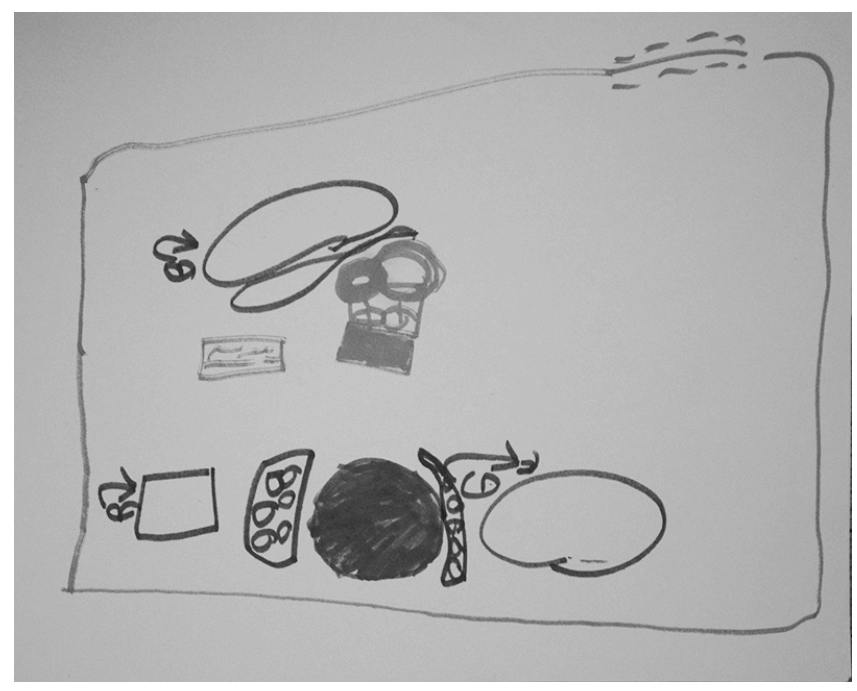

Figure 4: Ethan's drawing of the university laboratory school. The sandbox can be seen in the middle of the drawing.

Play is reflected in the program philosophy of the university laboratory school. The school's website states that the program is play-based with a focus on active learning which is derived from the children's interests. This appears to support King's (1979) study, which finds children distinguished play activities from work activities, by defining them as both voluntary 
and self-directed. The children from this current study, when at the university laboratory school, engaged in long self-directed play periods, and this focus on child-centred active learning may be why the children mention play and active learning frequently in their conversations and in their interviews, and did not mention the term 'work'. In contrast, when discussing their experiences in their current classrooms, the children make a distinction between work and play. King (1979) and Di Santo and Berman (2012) find teachers' use of the words 'play' and 'work' mirrors the children's understanding of the terms. Building upon this finding, it is possible to infer that the teachers in these current classrooms may distinguish between 'work' and 'play' and given the aforementioned placement of play in the daily schedule and the time it is allocated, the teachers may also reinforce teacher-directed 'work' as more important than child-directed 'play'.

Children's perceptions of their teachers. The children appear to view the teachers from their current educational setting and those from the university laboratory school setting in different ways. When asked what his current teacher does, Sebastian replies, "she teaches us what we are going to do for our work today." Emily states that her teacher "writes the morning message" and "she write[s] up the things of the day" so that the children know what they are doing that day.

Both Emily and Ethan acknowledge that their current teachers are different from their teachers at the university laboratory school, however, both children find it challenging to identify those differences. When asked about his past teachers Ethan states, "this is what I remember, they teach me stuff except not really ... but they teach me some." This appears to illustrate Ethan's awareness that the teachers at the university laboratory school and those of his current classroom employ different approaches to education. When asked if they taught him differently then his current teacher, he replies, "sure, yes it is" and when asked how it is different he comments, "by teaching kids different stuff." He then goes on to note that he did learn about math in both 
classroom settings, "so there's actually nothing" different. This may infer that although the same academic concepts are taught in the two classrooms, they ways in which the children were taught are different.

\section{Peer Relationships}

Dockett and Perry (1999) argue making friends at school is of great importance to young children and more recent research by these Australian academics confirms the importance of supporting positive peer relationships in schools. In their 2013 study, Dockett and Perry explore how friendship can be a potential source of support to aid children in the transition to school. They found that children, as part of the school community, engage in interactions with peers, which form "the bias from which they appropriate, reinvent and reproduce the culture of school" (Dockett \& Perry, 2013, p. 348). Peters (2003) further maintains that friendships can provide children not only with a sense of pleasure and companionship, but can also offer notable support for children's learning. Drawing from the 'new' sociology of childhood, it can be argued that such support can also help children navigate through their marginalisation in an adult-dominated world. This literature establishes that it is import for educators to explore how friendship can be promoted and nurtured in order to create a positive social-emotional climate within the classroom (Dockett \& Perry, 2013; Peters, 2003).

Given these findings, it is surprising that when discussing what aspects the children like about their current schools, only Sebastian makes reference to friends. This may indicate that within these classroom settings, the children's peer relationships are not being fostered and encouraged. In fact, the only times the children refer to other children by name in their current educational settings, are when they are commenting on children breaking the classroom rules. Ethan states, "Henry, a guy in my class, he always wants to chase the girls," and Matthew says, 
"Mason and Lucy are people who are like always silly." Within these statements, children refer to peers, not in terms of friendship, but in terms of not following the expectations of the classroom. It is possible to further infer that within these classrooms the teacher instils regulating regimes, or a system of rules, which work to constrain social interactions amongst children within the classroom. Peters (2003) argues that educators need to be aware of how they position children within their classrooms and how this impacts the children's peer relationships. Emily notes that her teacher assigns children to specific desks so that “you don’t talk to people.” Pech (2013) argues that the ways in which educators interact with children sends a message about what is important and valued in the classroom. Within this aforementioned setting, the teacher appears to value maintaining discipline over encouraging sociality.

The children's descriptions of their current classrooms is at odds with the recommendations made by the authors of the Full-Day Early Learning-Kindergarten Program (2010) document which maintains, "a safe and supportive social environment in a school is founded on healthy relationships" (p. 44) and recommends that in order for children "to experience themselves as valued and connected members of an inclusive social environment, children need to be involved in healthy relationships with their peers" (p. 44). Additionally, a supportive social environment is one of the four components of a healthy school as identified by the Ontario Ministry of Education's Foundations for a Healthy School (2012).

In comparison, when reflecting on their experiences in the kindergarten program at the university laboratory school, the children mention their peer's names when discussing friendship and elements that they miss about the classroom. Sebastian states, "I remember Lucas... He was one of my friends." Matthew discusses how he still maintains a friendship with Sebastian and that he has "play dates with him." Ethan discusses his past friendship with Emily, and although they now attend the same school he notes, "I miss her a lot, and she is still in the class except you 
know why I still miss her? Cause we almost never see each other still.” As it will become apparent shortly, the theme of friendships features predominantly throughout the children's reflections of their experiences at the university laboratory school. This may indicate that this setting fostered and promoted peer interactions.

A notable difference in the children's drawings of their current classrooms and their drawings of the kindergarten room at the university laboratory school, is that people do not feature in the drawings of their current classrooms (Figure 1, 2 and 3), however, people are present in two of the three drawings of the university laboratory school (Figure 4 and 5). Hannah drew a picture of the slide in the playground, she then drew a figure on the slide, She explains, "it is someone going down the slide." Emily drew a figure in the daily living centre of the classroom and notes, "some people are playing there ... she is holding the pan so she can cook." In the centre of the drawing she placed another figure and stated, "this is the place where we walk." These statements and drawings, along with the mentioning of friends throughout the conversations, appear to indicate that when remembering the university laboratory school, friendship and peer interactions are intrinsically linked to the setting. It may further be inferred that this setting, more so than their current classrooms, encouraged and helped to establish peer interactions.

Friendships may offer children both a sense of enjoyment and support. Devine (2002) acknowledges the importance of friendship and "child culture" particularly when navigating their subordinate social positioning in schools. Teachers and school environments that hinder, rather than foster peer interactions, can increase the power imbalance between adults and children within learning environments. Rules also aid in maintaining the hierarchical order of classrooms, and this will be further explored in the subsequent section. 


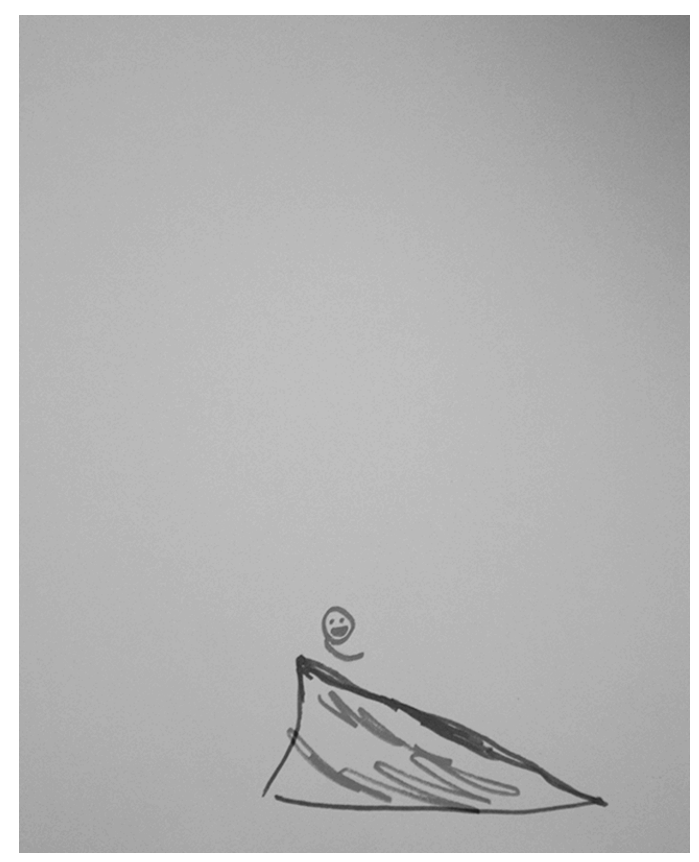

Figure 5: Hannah's drawing of the university laboratory school. A figure is shown going down a slide.

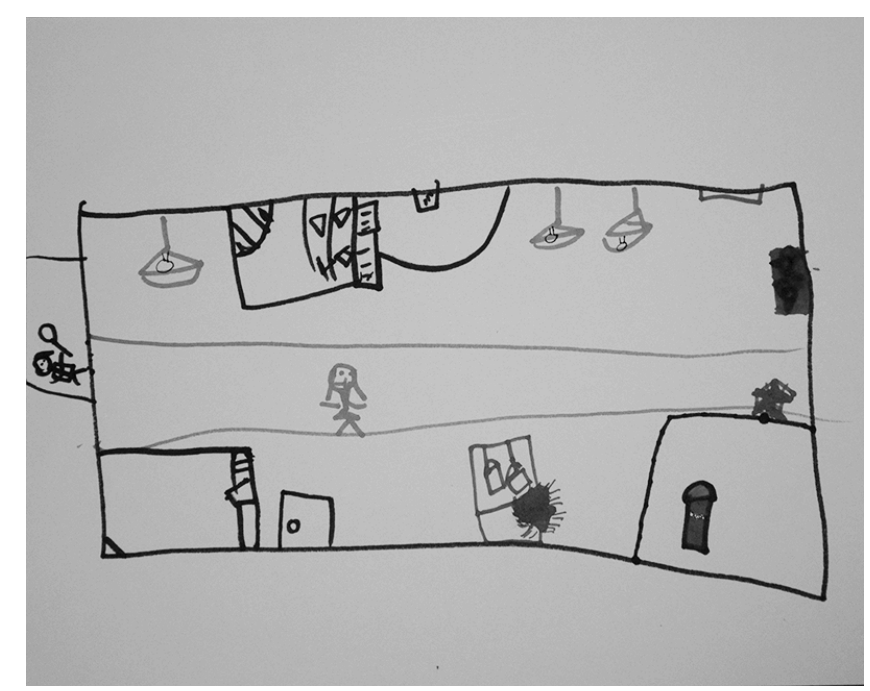

Figure 6: Emily's drawing of the university laboratory school. Two figures can be seen in the classroom.

\section{Rules}

When the children are asked what a child unfamiliar with the classroom would need to know about their current classrooms, rules feature predominately. These findings appear to mirror Dockett and Perry's (2005b) findings from the Starting School Research Project, which reports children often mentioned rules they thought other children needed to know before starting school. Ethan states that a child would need "to learn the rules of the class" and Matthew maintains it would be important for the child to "listen to the teacher." This indicates that the children are aware of what is expected of their behaviour in a school context. Dockett and Perry (1999) argue that children's awareness of rules indicates their understanding of the hierarchical nature of school. They maintain that children are likely to accept the power of teachers and 
principals to create and enforce rules, as these are the people children perceive to hold the power in school contexts.

Fielding (2000) describes the school classroom as "a 'hot bed' of moral geographies - of moral codes about and where children ought to learn and behave" (p. 231). Some of the rules in schools and in classrooms, to which children are expected to comply, are explicit, others, however, are implicit. Implicit rules can be understood as, what sociologists refer to as, the 'hidden curriculum.' Skelton (1997) defines a hidden curriculum as a "set of implicit messages relating to knowledge, values, norms of behaviour and attitudes that learners experience in and through educational processes" (p. 188). It functions as a form of social control. The children's conversations indicate that the children are aware of what is expected of their behaviour in their classrooms' contexts. Hannah states that it would be important for a new child in her current classroom to know how to "sit in the five-point check." She goes on to explain that this is a checklist of how children must sit and behave during carpet time. She goes on to list the elements of the checklist, "hands in your lap," "listening ears," "quiet" and "looking at your teacher." These are explicit rules of the classroom that appear to be openly stated by the teacher. Although not explicitly stated by the teacher, the implicit rule of this setting is that the teacher is the one who holds all the power and control of the classroom. In this learning environment, the teacher exerts control of, and maintains power over the children through the employment of strict rules of behaviour. Within this context, classroom rules are what Millei and Raby (2010), drawing from Foucault (1979), describe as "a technology of the school to deliver social training and to regulate the student population" (p. 28).

When I ask Hannah to tell me about her teacher she replies, "my teacher's name is Mr. Woodly, and if you are being silly you have to go to the white chair and you have to think about what you have done." I believe it is significant that the first thing Hannah chose to tell me about 
her teacher, beyond his name, was what happens to children when they are 'silly,' or do not uphold the expected behaviours of the in the classroom. Matthew also discusses the use of timeout practices in his classroom. He states, "if you are not listening you have to go in time out... it's where you have to go off the carpet and sit in a chair and do nothing." Both children identify practices in which teachers single out children and remove them from group situations in order to promote compliance and maintain control of the children. When I ask Hannah what is considered being silly, she replies, "talking or doing actions with your body." Within this classroom during carpet time children are expected to sit still and remain quiet, so not to 'disrupt' the on-goings of the classroom. Foucault (1979) states that, within the institution of school, punishments are handed out to children for the "slightest departures from correct behaviour" (p. 178). Time-out is a means in which the teachers condition children to the "submission of classroom rules as a result of punishments and rewards, and because of the authority of the teacher" (Millei, 2012, p. 88-89).

Classroom rules are often autocratic, not democratic. They "are frequently presented as fostering responsibility, respect and self-discipline, yet rules are top-down and hinge on mute obedience" (Raby, 2008, p. 77). Children are often not permitted or empowered to create, modify or challenge classroom rules through classroom discussions (Thornberg \& Elvstrand, 2012). Classroom rules, which foster unquestioning compliance, uphold the authority of the teacher in order to maintain 'control' of the classroom, and do not foster children's critical and reflective thinking. This lack of critical thought, and democratic practice will be explored in the following section.

\section{Decision-Making/Influence on Curriculum}

Through their conversations and drawings, the children discuss the extent to which they are active in asserting their agency within their classrooms settings. Dewey (1916) argues in order for people to continue to live democratically, they must have opportunities to learn, the 
meaning of a democratic way of life and how it may be realised. The importance of fostering critical thinking is affirmed by the Full-Day Early Learning-Kindergarten Program (2010) curriculum document, which recommends the development of critical thinking skills in order for children to evaluate situations and ideas "in order to understand them fully, identify their implications, make a judgment, and/or guide decision making" (p. 45) and not to "merely accept the obvious as a given" (p. 45). How children's agency is realised and supported within a classroom setting is dependent on the ways in which teachers conceptualise children and their roles as educators.

The caretaker model. Raby (2008) refers to the caretaker model as one in which children's rights are carried out by adults and “in which children are prepared for future selfgovernance and decision-making through an absence of participation in the present" (Raby, 2008, p. 78-79). As mentioned above, teacher-directed activities and teacher-organised spaces dominate the children's conversation about their experiences in their current classrooms, as does the aforementioned discussion about the distinction between play and work. As described previously, King's (1979) study found that children distinguish play activities from work activities, by defining them as both voluntary and self-directed. In the children's current classrooms, however, play activities appear to at times be directed by adults.

When discussing her current classroom, Hannah states that during playtime, "sometimes the teacher asks you what centre you want to go to, you have to tell her or else you can't go to any centre." When I ask Matthew if he chooses where to go during playtime he notes,

Sometimes, but sometimes we don't have to tell them where we want to go. Sometimes they say free playtime and that means we don't have to tell them where to go, we can just go without telling them or asking them. That's free time. 
He goes on to state that is it is not free playtime, "you have to tell the teacher what you want to play in." In both Hannah's and Matthew's current classrooms playtime is, at times, controlled by the teacher. Teacher-directed playtime seems inherently paradoxical. Children value play as selfdirected (King, 1979), and yet in these classrooms the teachers appear to control this activity as well. Do the teachers see the children as incapable of making their own decisions and monitoring their own behaviours during this time?

When asked whether he has the opportunity to choose what to do during playtime, Sebastian states, "we get to do what we want," however, he does note that when playing with the bins on the carpet, if a child wants to play with more than one other person, "you have to ask the teacher." Although the children can choose which activities they participate in, there are still conditions as to how the children are to play. I question the motives behind theses teacherimposed restrictions to playtime. Are they employed by the teachers in order to further maintain control of the classroom? Do the teachers view the children as incapable, in need of constant assistance? Whatever the reason, these restrictions limit the opportunities for the children to engage in decision-making and in problem solving, and, therefore, in critical thinking. Freire (2000) discuses the "paternalistic student-teacher relationship" (p. 32) which positions children as subordinate, and argues that educators must refuse to be tempted by the view that children are inherently incapable. In order for teachers to support children in establishing their agency and developing their critical thinking skills, they need to recognise how they view children in society.

Children as social actors. When reflecting on their experiences in the kindergarten classroom at the university laboratory school, the children often mention activities that are active. The children in this classroom engage in long self-directed play periods, and this focus on childcentred active learning may be why the children mention active play activities frequently in their conversations and drawings. This appears to follow the recommendations of the Full-Day Early 
Learning-Kindergarten Program (2010) curriculum document by "allowing children to be 'in charge' of their play - engaging them in the planning of the learning activities and allowing time for unstructured play" (p. 14). This may be why, as previously mentioned, the sandbox was a dominant feature of the children's recollection of their experiences at the early learning. This sandbox, and its pulley system, allows children to actively explore, to test hypothesises, and to make decisions.

Within this learning environment, it appears children at the university laboratory school are given opportunities to decide where and how to play. They are given opportunities to make decisions and act upon them. Echoing the writings of Dewey, Matthew and Limb (1999) maintain, "democratic responsibility is acquired only through practice and involvement. It does not arise suddenly in adulthood through maturation" (p. 66). Children who are given opportunities to exercise their agency in the classroom may be better prepared to be active democratic citizens, not just in the future, but also in the present.

The power to change. As important as children having opportunities to make decisions and influence curriculum, is children's belief that they have the power to make such changes. This, as laid out in the CRC is in fact, the right of all children. Articles 12 and 13 of the CRC (1989) state that all children have the right to form and express their opinion on matters that affect them and that they have a right for these views to be heard.

It is significant that when asked if they would change anything about their current classroom experience, only Emily mentions that she would add a playground to her classroom. The other children say they would not change anything. One could assume that this confirms that the children are content with their current situation, however, I would argue that children, and adults, should be encouraged to continually question and strive for change in order to improve 
situations, and that the children's responses should be viewed as further illustrations of the power imbalances and hierarchal structures present in school environments and in society at large.

Devine (2002) states "children are positioned as subordinate within the school, with negative implications for their perception of themselves as active contributors to the schooling process" (p. 303-304). This is reflected in Stafford, Laybourn, Hill, and Walker's (2003) study that finds students did not ask for certain changes in their school because they believe they cannot change them, in other words, that the school's policies are too inflexible. Further, Thornberg and Elvstrand's (2012) study report some children believe that children are not capable of making "good" decisions in the classroom, as they only want to do "fun things." Drawing from the "new' sociology of childhood Punch (2012) maintains that children are so accustomed to being marginalised in society that they are used to adults positioning them as inferior. Their subordinate status has become normalised. Foucault (1979) discusses the "judges of normality" that are present throughout society, and further notes

We are in the society of the teacher-judge, the doctor-judge, the educator-judge, the 'social-worker'-judge; it is on them that the universal reign of the normative is based; and each individual, wherever he may find himself, subjects to it his body, his gestures, his behaviour, his aptitudes, his achievements (p. 304).

The institution of school, through its familiar practices, upholds and promotes dominant normative societal assumptions, including the conceptualisation of children as incompetent, dependent and naive. This construction of children must be challenged, particularly in educational settings, in order for children to "locate themselves as subjects (and rights-holders) in the present, rather than in the future" (Raby, 2008, p. 78).

\section{Summary: Implicit and Explicit Comparisons Between Learning Environments}

I now reflect back on my research questions of: What are children's perceptions about their past experiences in a university laboratory school and about their experiences in their 
current learning environment? How do children compare these experiences directly and indirectly? When asked to directly compare the two learning environments, the children's explicit comparisons tend to focus on the physical space. For example, Matthew states, "one classroom is bigger and the other is smaller" and Hannah notes that her current classroom does not have "as much centres as [the university laboratory school]". What is striking, are the implicit comparisons of power and hierarchical structures in their different educational settings as alluded to by the children throughout their conversations and drawings. It is significant that when given the opportunity to discuss any aspect of their current learning environments, so much of what was discussed revolved around issues of power imbalance within the classroom. This research project uncovers a disappointing reality, not only are issues of power imbalance and hierarchical structures prevalent in these children's lives, but pedagogical practices often reinforce these dominant and normative views. This study presents children's perspectives about their experiences in different learning environments in order to unpack and challenge dominant views of childhood and of pedagogical practice. I will explore some recommendations for future practice and identify some possible areas for further research in a following section, however, I will now discuss some of the strength and limitations of this research project. 


\section{Strengths and Limitations}

\section{Trustworthiness}

As previously mentioned, this qualitative research study does not aim to uncover, or to declare any universal truths. Employing a constructivist paradigm, this study seeks to explore the lived experiences of the participants, and through analysis, establish thematic connections amongst the data. When addressing trustworthiness within this approach, it is important to consider both, "the story told by the research participant and the validity of the analysis, or the story told by the researcher" (Riessman, 2008, p. 184). Guba (1981) suggests examining the validity of these stories through four aspects of trustworthiness: credibility, transferability, dependability and confirmability.

Credibility. Guba (1981) maintains prolonged engagement at a site, peer debriefing and triangulation can all aid in establishing credibility within a research study. Prolonged engagement at a site can help the participants become familiar and comfortable with the researcher. A prolonged time spent with participants in their setting adds to the credibility of a study's findings (Creswell, 2014). Although the data collection took place over a relatively short time period, I have spent a considerable amount of time with each participant at the university laboratory school prior to the data collection. This pre-established relationship, which is discussed in more detail shortly, allowed the children to be more familiar and confortable with me during the data collection.

Guba (1981) recommends peer debriefing as a means to establish credibility in order for a researcher to "to test their growing insights and to expose themselves to searching questions" (p. 85). Throughout the research process, I met with my supervisor to discuss the project at various stages. Through private discussions, in order to help maintain the anonymity of my participants, I 
discussed the raw data and my interpretations and analysis of the data with my supervisor in order to ensure that the findings will resonate well with others (Creswell, 2014).

Triangulation, or the process of establishing themes drawing from multiple data sources and perspectives, can add to the validity of a research study (Creswell, 2014). This research project employs a variety of data sources and perspectives, which aid in confirming the data and interpretations (Guba, 1981). Conversations and drawings were used to gain insight into children's perceptions of their experience in different education settings. A variety of theoretical frameworks including, the 'new' sociology of childhood, critical studies, critical pedagogy and a child rights-based perspective were employed to help interpret the data.

Transferability. Although a small sample size is not so much a limitation, but a quality of qualitative research, it is important to acknowledge that this research study employs a small sample size from a specific context. It is important to document such perceptions and experiences, as this not only helps to establish children as experts on their own lived experiences, but may also identify areas for future research within the fields of early childhood studies and education. These results, therefore are not generalizable to be representative of all children's perceptions and experiences, however, some ideas and theories generated by the research may be transferable to other contexts. Within qualitative research the reader "should be able, on the basis of a thick description and the provision of a vicarious experiential account, to determine if and how these experiences can be used to understand a new setting” (Hellström, 2008, p. 324). Drawing on detailed accounts and incorporating direct quotations from the participants, this study aims "for interpretation of the meaning and context to be vivid and visible" (Whittemore, Chase \& Mandle, 2001, p. 532). 
Dependability. Guba (1981) argues that researchers select methods that are complimentary. These methods should overlap in such a manner that "the weakness of one is compensated by the strengths of another" (Guba, 1981, p. 86). The use of drawing as a data collection tool will be discussed in more depth in a following section, however, this data collection method provided the children with an additional means of expression. Drawings are subjective, and it is important that I did not place a meaning on the drawings that was not intended by the children. It was essential that the children themselves discussed the elements of their drawings and that during the analysis stage these drawing were analyzed along side, not dependent from, the children's spoken descriptions.

Confirmability. Guba (1981) maintains that it is critical for a researcher to practice reflectivity throughout all stages of the research project. Reflectivity should be central to the research process, as researchers should reflect not only on their social location and assumptions, but also on their methodology and choice of data collection tools (Punch, 2002). Through all stages for the research project I have been transparent of my epistemological assumptions and social location. I have identified the conceptual and theoretical frameworks that influenced all stages of this study from topic selection through to analysis. This reflectivity aims to establish a trustworthy narrative.

\section{Risk}

During the ethics application process, I hypothesised as to some of the possible risks to participants this research study may present. I classified the potential risks of this study as low, however, as I was asking the children to reflect on past experiences, it is possible that a participant may reflect on unpleasant memories while responding to a question and become upset or feel anxious. Should this occur, I outlined in the ethics application, that the participant would 
be informed of that he or she might take a break, choose not to answer a particular question, or discontinue participating, if they wished, for any reason.

This risk did occur during my data collection, however, it was not due to recounting and unpleasant memory, but a pleasant one. The day after meeting with Emily, I received an email from Emily's mother informing me that after I had left her house, Emily had cried and said that she missed her time at the university laboratory school. I replied back to her mother that I was sorry Emily was so upset and to let me know if she would like to come by the laboratory school for a visit. Her mother replied that Emily was currently working on designing a time machine "which can bring the old days back."

The risk of recalling an emotionally unpleasant, or happy, memory in research, is not a challenge of research with children, however, a risk of social research, particularly employing oral history, with all humans. Researchers need to be aware that inviting people to recall life events might uncover strong emotions in their participants. This can occur at any stage of the research process, and the researcher's responsibility to his or her participants does not end at data collection.

Although potentially emotional, when handled appropriately, I believe the emotional response to personal reflection on past life experiences is a strength of qualitative research, especially of research working within a constructivist paradigm. Life stories and human emotion provide researchers with thick descriptions, often unobtainable from other sources, which can aid in producing a more nuanced and insightful research study. Emily's powerful response to her reflecting on her experiences of the university laboratory school adds additional insight and credence to her discussion of the university laboratory school and how she compares this setting to her current learning environment. The description of her wanting to create a time machine in 
order to return to her old classroom is a powerful one, and adds an additional layer to her reflections.

\section{The Researcher's Position}

I believe that my past experience, and current perspectives and subjectivity are not a bias, but serve to add further insight into this research project. My background provides me with what I believe to be an emic approach to this research project. An emic approach considers research from within the system itself (Gardiner \& Kosmitzki, 2010), and has often a greater understanding of the social and cultural context of the setting. This insider approach, although it had its challenges, allowed me to research from within a context of which I was already familiar.

I did have a pre-existing relationship with the children of this study. The children knew me as a parent of one of their peers, and as a supply staff from the university laboratory school, however, this project asks the children to accept me in a third role, as a researcher. The children, who participated in this study, once I explained my role as a researcher, all accepted me as that.

At times during the research process, my pre-established relationship with the children presented a challenge. During recruitment I did not want my relationship with the children and their families to influence their families decision to participate. As mentioned earlier, the manager of the university laboratory school was the one who first contacted the possible participants, and on the consent form it was explicitly stated that participation in the study was entirely voluntary.

During data collection, the children had a choice to participate by the use of an assent form. Dockett et al. (2009) maintain the importance of gaining children's assent to participate further to parent's consent. This process further allowed for me to establish the voluntary nature of participation in the study. Although assent is gained at the beginning of the data collection, it 
is critical assent is considered throughout the data collection (Cocks, 2007). The researcher must remain aware of any clues, visual or verbal, that children may give to indicate that they no longer which to participate in the study. I was aware of these clues, and throughout the conversations with the children, I asked if they still wanted to participate, and respected their requests to end the data collection when indicated by the children. This awareness of visual and verbal cues aided me in ensure my pre-established relationship with the children did not influence the voluntary nature of their participation.

I believe, however, my pre-existing relationships with the children proved beneficial during the data collection stage. Many researchers conducting research with children maintain the importance of building rapport with children prior to gathering data (Irwin \& Johnson, 2005; Punch, 2002). I believe my prior relationship with the children did increase the comfort level of the children, as I am used to speaking with them and they are used to speaking with me. When I fist sat down with Emily she recalled an art activity I had done with her at the university laboratory school. This discussion of our previous relationship, created a level of comfort from the beginning, which I would argue would have been difficult to achieve if I was unknown to her. After I thanked Ethan for taking the time to speak with me, he turned to me and asked, "want to play?" This further illustrates the children's comfort with me, as Ethan extended an invitation for

me to remain at his home after the data collection. My pre-existing relationships with the children allowed for a comfortable rapport during the conversations and aided in establishing a degree of intersubjectivity, which Rogoff (1990) defines as "the mutual understanding that is achieved between people during communication" (p. 67).

\section{Reflecting on the Data Collection Process}

In the methodology section of this study, some of the benefits and challenges of employing drawing as a data collection tool were discussed. I asked the five children 
participating in the study to draw a picture of their current classroom as well as a picture of what they remembered of their kindergarten classroom at the university laboratory school. Three of the children drew pictures of both settings. These drawings provided me with additional insight that would have been difficult to gather from the conversations alone. Although I am familiar with the layout of the university laboratory school, I have never seen any of the children's current classrooms. The drawings provided me with a sense of the visual layout of the room as well of the furniture and specific materials of the different classrooms. These drawings served as visual tours, by which the children were the tour guides and could illustrate to me what was important to them in each setting, not only points of interest which, I as a researcher believed to be important. I believe the use of these tours via the drawings helped to reduce some of the power imbalance between the children and myself, as the children took control of some of the data collection by choosing which aspects of their classrooms they wished to discuss with me.

While selecting the data collection tools, I was conscious of selecting tools that not only would help to generate the most pertinent data for my research questions, but also tools which would be most meaningful and relevant to the children participating in the study. I selected drawing, along side conversations, as I wanted to provide children with an activity with which they were familiar, and with a method which provides an alternative means of communication. It is, however, important to acknowledge that not all children wishing to participate in a research study may want to draw. Einarsdottir et al. (2009) note that some children believe they cannot draw, or that their drawings are not any 'good'. When I asked Matthew if he could draw a picture of his current classroom he replied, "I don't really know how to draw the things." Matthew then went on to tell me that instead he would draw the blocks that he enjoys playing with (see Figure 7). Although Matthew appears unsure of his capabilities of drawing his classroom, he does want to draw, and he continues to draw throughout the interview. Even near the end of our 
conversation when I asked Matthew, "Do you want to stop now? Or do you want to keep drawing or talking?" he replied, "drawing." Einarsdottir et al. (2009) further maintain that by drawing during the data collection, children may feel more comfortable as they do not need to maintain eye contact with the researcher, and they are engaged in an activity that is familiar to them. This appears to be the case with Matthew, as although he does not draw his past or current classroom, he appears to enjoy, and to be at ease with, the process of drawing while conversing.

Alternatively, Sebastian did not wish to draw during the data collection process. When I asked Sebastian if he could draw a picture of his current classroom, he replied, "or you could visit my class" and then he goes on to state "I don't really remember what it looks like." Dockett and Perry (2005b) argue that, listening is not a right, that some children may wish to remain silent, and it important to respect that. Sebastian, especially nearing the end of the conversation, responded to various questions by saying he does not remember. Although one could interpret this as a lack of memory, when paired with his body language, it appeared to indicate that he did not want to continue with the interview. I asked him if he would like to stop talking, and he replied, "yes."

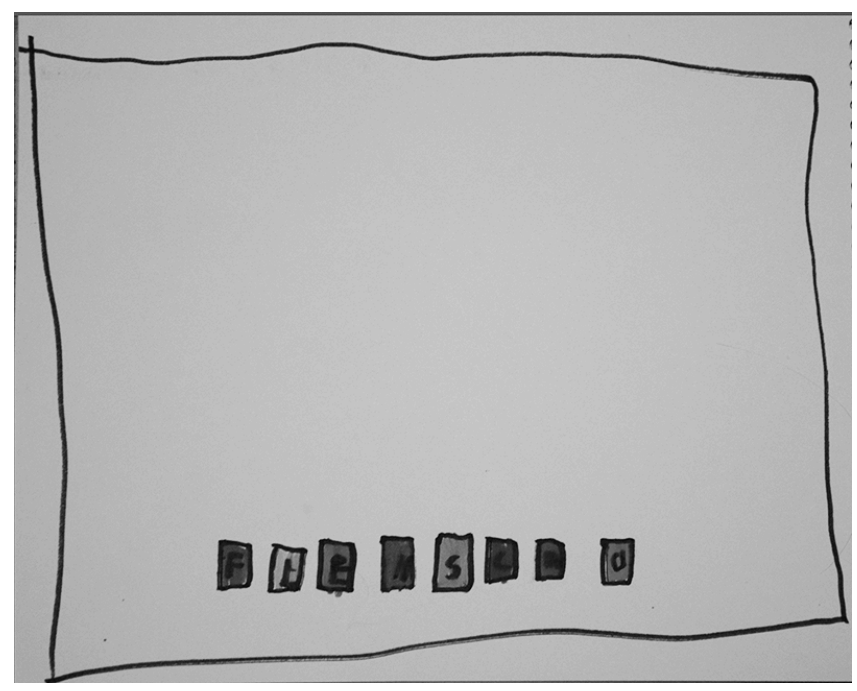

Figure 7: Matthew's drawing. 


\section{Recommendations}

This research study generates knowledge on the perceptions of children who have experienced different learning environments. By speaking with children first-hand, not only does this research project give a voice to an often silenced group, it presents some interesting themes, which may not only increase knowledge in the field of early childhood studies and education, but also identifies further areas of research. The following section will discuss several recommendations to the field of early childhood studies and education, and identify areas for future research.

\section{Pedagogical Practice}

The construction of play and work. When discussing their experiences in their current classrooms, the children appear to make a distinction between play and work activities. The children use the term 'play' to describe child-directed active activities, and 'work' to refer to teacher-led passive learning activities. Teachers should be mindful of how work and play are constructed in their classrooms. The construction of play and work as dichotomous may lead to favouring one activity over the other. In these classroom settings, play is associated with more active activities such as drawing and painting, and work as more academic activities, such as math and reading. It should be the aim of all classrooms to establish positive school perceptions, however, a dichotomous construction of play and work may lead to children disfavouring the more traditionally academic activities. As argued by the Full-Day Early Learning-Kindergarten Program (2010) curriculum document, play and work should not be viewed as opposing entities, but should be intertwined within the classroom environment. Learning through play may aid children in fostering positive school perceptions of all subject matter, a benefit both to children's current and future learning. 
Encourage active versus passive learning. Despite children stating that they enjoy participating in active activities, the children report they often engage in teacher-led passive learning. In their current classrooms, the learning the children appear to participate in is reflective of Freire's banking model of education in which learning is one-directional, as children passively receive the 'knowledge' from the teacher. Ethan acknowledges that he believes this is how his teacher thinks children learn, "except really it's not for me".

Dominant Euro-American society “often assume that children's learning occurs by their being recipients of explicit instruction that is organised and directed by adults" (Rogoff, 2003, p. 301). This model of learning is normalised in Western schools and classrooms. Woodhead (2005) states, “there is nothing natural about the institution that dominates so much of children's lives the school" (p. 90), however, in Western society the banking model of education is often viewed as normative and favourable. Rogoff (2003) maintains children learn as they participate in cultural activities, and recommends her concept of guided participation, in which children actively participate in learning, guided by adults. This notion further supports Freire's (2000) recommendation of bidirectional dialogue between children and educators within the classroom. These recommendations appear not only to be supported by the views and experiences of the children from this current study, but by establishing a learning environment in which children are actively engaged in the learning process, educators relinquish some of the power they hold over children, thereby confirming children's rights to be viewed as active and valued members of their societies

Provide opportunities for democratic engagement. As argued by Dewey (1916) and Moss (2007), democracy is best learned by every-day, first-hand experiences and social interactions in schools and in classrooms. Within their current classrooms, the children appear to have limited opportunities to make discussion and influence the routines and curricula of the 
classrooms. Descriptions of rules, and what happens to children who do not obey these rules, feature in the children's discussions. Children should be given opportunities to be involved in the construction of what is expected classroom behaviour, rather than demonstrating unquestioning obedience. Children's classroom activities appear to be heavily monitored and controlled by adults, with even 'playtime' being, at times, teacher approved and directed. Children should be given opportunities for self-initiated and self-directed activities, where they can employ and build upon critical thinking, decision-making, and social interaction skills. Not only will these opportunities help to develop important skills, the very presence of them will help children to view themselves as rights-holds with a valuable position in society.

In Canada, particularly Ontario, young voters are often criticised for being apathetic. There is a dominant societal belief that young people are uninterested in politics. This places the blame on the individual. I argue that we need to move from viewing young populations as indifferent in the democratic process to looking at how society has limited their democratic voice. How can one expect a population, who has been continually told, explicitly and implicitly, that their views are not important, or are not mature enough to count, to suddenly believe that their opinions do matter just because they have reached the age of majority? Society must support children in establishing their agencies, and provide them with opportunities to make decisions on matters that affect them; after all, it is their right.

\section{Teacher Education and Training}

Fullan (2001) states, “educational change depends on what teachers do and think - it's as simple and as complex as that" (p. 115), and yet, as with all humans, educators are "embedded in cultural, historical, institutional, and social context" (Thornberg, 2010, p. 930). It is important to acknowledge the institutional constraints on teachers in changing their practices including, class 
size, unsupportive administrators and/or school boards, and dominant societal conceptualisations of school, however, with appropriate pre-service education, continued professional development, and the appropriate support, I believe teachers can be fundamental in breaking the cycle of how society views children and education, and in validating the importance of acknowledging children as experts in their lived experiences.

Through their conversations and their drawings, the children identify several issues in their classrooms concerning power imbalances and hierarchical structures. Poimenidou and Papadopoulou (2013) maintain, "education plays an important role in the formation of social identity but at the same time it triggers inequality among members of a society" (p. 167). Through dominant practices and views that have been normalised in the educational system, classrooms have upheld society's positioning of children as marginalised and subordinate to adults.

Within early childhood pedagogy, Lee and Johnson (2007) identify folk psychologies, which are notions teachers hold of how children learn, and folk pedagogies, which are "taken-forgranted practices that emerge from deeply embedded cultural beliefs about how children learn and how teachers should teach" (p. 240). Deeply rooted in these folk psychologies and folk pedagogies are the teachers' conceptualisations of children and childhood. It is important for educators to be cognisant of these views, and of "taken for granted power and interaction patterns" (Thornberg \& Elvstrand, 2012, p. 52) in order to more effectively reflect on, and reevaluate their classroom practices, and the possible constraints the dominant culture has placed on pedagogical practices, and on children's learning.

Harry (1997) describes teachers as either, "leaning forward" or "bending backwards" in their efforts to collaborate with families in educational settings. This descriptive image can be applied to teachers' willingness or reluctance to challenge and re-evaluate their educational 
beliefs and practices. I argue, educators can, and must, be agents of change. Teacher training and professional development, incorporating critical pedagogy studies, can be a means of producing

educators who may become key agents of enabling systemic change rather than further upholding the assumptions deeply embedded in dominant and normative views and practices.

Critical pedagogy offers a theoretical framework by which to deconstruct dominant practices, however, it is imperative to also reconstruct these practices. This framework offers insights to re-examine normative practices, however, these insights are not fully beneficial to children unless practices and curriculums are re-built to reflect this newly generated knowledge. Educators and administrators need to work together to challenge dominant constructions of children, and to deconstruct standard and familiar school practices and curriculum. In doing so, educators can assist children in developing "tools that empower them to speak against injustice, inequity, and also to change unfortunate realities" (Milner, 2013, p. 39). These recommendations, by their very essence, will challenge normative practice, allowing for more equitable power structures within children's learning environments.

\section{Future Research}

When reflecting on their experiences within different educational settings, children did not refer to 'work' at the university laboratory school, but did when discussing their current classrooms. This distinction is significant and may reflect a more play-based curriculum in one setting over the others. This recognises a possible area for future study of how children's exposure to different curricula may influence how they view work and play, and how this distinction may influence children's preference of different learning activities.

This research project identifies some of the differences between the university laboratory school system and the public school system, as identified by children. My previous research project, at the university laboratory school, establishes the school's kindergarten program as a 
model for full-day kindergarten (Barnikis, 2013). Despite the kindergarten program at the university laboratory school serving as an exemplary model for full-day kindergarten, its future is uncertain, as with the full implementation of full-day kindergarten in September 2014, childcare subsidy will no longer be offered to children who attend a kindergarten program outside of the public school system. Although the children from this current study establish many exemplary aspects of the program, there is a disappointing reality that a model for quality programming is at risk of not surviving even before the program for which it serves as a model is fully realised and evaluated.

I believe that this illustrates the need for further research on the benefits and importance of university laboratory schools, and for the need of this knowledge to be disseminated to the greater society. This could also lead to an investigation into the qualities of the teachers at the university laboratory school. Within this current study the teachers of the university laboratory school are discussed in terms of their differences from the teachers in their current classrooms. They are often described in terms of what they are not. Further research should be conducted in order to establish what distinct qualities these teachers do possess. For example, an additional study asking the children to draw not only their classrooms, but also their teachers could generate additional data on the qualities of the laboratory school teachers. Only once this information is more widely acknowledged, will it be possible for programs like the one offered by the university laboratory school to be recognized, and hopefully then receive the funding and support necessary for survival. 


\section{Conclusion: Final Thoughts}

This research project had two aims. Firstly, to explore children's perceptions and comparisons of their experiences in two different learning environments, and secondly, through the research process, to establish children as competent experts on their lived experiences. Although interlaced, through the realisation of these aims, innovative and significant information is generated and explored, which leads to recommendations for future practices and to identification of areas for further research.

The questions regarding their learning environments that were discussed with the children were very broad and open-ended. It is significant, that when selecting which aspects of their current classrooms to discuss, so much of the children's conversations centred on issues of power imbalance. These issues are explored through the children's descriptions of space, pedagogical practice, peer relationships, rules, and their decision-making and influence on curriculum. This uncovers a disappointing reality that a substantial proportion of these children's experiences within their current classrooms are dominated by power imbalances and hierarchical structures.

Through their explicit and implicit comparisons, there is a notable difference in the children's discussions of their experiences in the kindergarten program at the university laboratory school. The children's accounts of their experiences within this setting are distinctly not dominated by issues of power imbalance and hierarchical structures. Historically, university laboratory schools have been established to provide a service to researchers, families and children, as well as acting as a model of high quality and care (Barbour, 2003). Despite the aim of the aforementioned university laboratory school's kindergarten program to be a model for the full-day kindergarten program, its existence is being challenged. This, along with the findings of this current study indicates an area of future study into the benefits and importance of university laboratory schools. 
As laid out by the United Nations (1989) Convention on the Rights of the Child, children have the right to influence their learning processes, as well as their learning environments. Schools are institutions in which children have a right to voice their opinions and concerns, and to be heard. This study illustrates that children are competent informants of their experiences, past and present, in different education settings. Their conversations illustrate the children's knowledge and understanding of their experiences and learning. Furthermore, current literature not only asserts children as component informants on their experiences in learning environments (Dockett \& Perry, 2005a, 2005b; Einarsdottir, 2010), but also their desire to be consulted on issue relating pedagogical practices and curriculum (Glazzard, 2012; Rosen, 2010). If children are able and willing to be consulted on issues of pedagogical practice and curriculum, why is this not the normal approach when implementing educational services and policies?

As Thornberg (2010) states, we need to challenge "the hegemony or dominating discourse of the subordinated and incompetent child in our society" (p. 930). By unpacking dominant and normative educational practices through a lens of critical theory and critical pedagogy, educators can become key agents in challenging the established view of children as incompetent, dependent and naive. It is my hope that a recognition of children as competent social actors, will lead to a society that recognises, not only the positive influence adults can have on children, but also the positive impact children can have on adults, pedagogical practice and society at large: a society, which celebrates children as significant citizens of the present, not just of the future. 


\section{Appendix A: Participant Recruitment Email}

\section{Dear Families,}

Tiffany Barnikis, as part of her graduate degree in Early Childhood Studies, is conducting a major research project exploring children's perceptions of their learning environments. Through this study, Tiffany wishes to explore how children perceive, remember and compare their experiences at the Ryerson Early Learning Centre with their experience at their current school. Tiffany is looking for children to interview. The interview will include open-ended questions as well as the participating child drawing pictures of his/her classrooms. Through this study, Tiffany aims to acknowledge children as experts on their lived experiences. The names of all children and schools will be replaced by pseudonyms in order to protect confidentiality. The time commitment of the interview will be approximately 20-30 minutes. If you would like to have your child participate in this study, or have any further questions please contact Tiffany directly at tbarnikis@ryerson.ca. Involvement in this study is completely voluntary and you may withdraw from the study at any time without consequences of any kind. The Ryerson University Research Ethics Board has reviewed this study.

Thank you, 


\section{Appendix B: Consent Form}

\section{CONSENT TO PARTICIPATE IN RESEARCH}

\section{CHILDREN'S COMPARISON OF TWO EDUCATIONAL ENVIRONMENTS}

Your child is being invited to participate in a research study. Please read this Consent Form so that you understand what your child's participation will involve. Before you consent to participate, please ask any questions necessary to be sure you understand what your child's participation will involve.

\section{INVESTIGATORS}

This research study is being conducted by Tiffany Barnikis and Dr. Rachel Berman, from the School of Early Childhood Studies at Ryerson University. The results of this research project will contribute to the major research paper for Tiffany Barnikis' graduate degree.

If you have any questions or concerns about the research, please feel free to contact: Tiffany Barnikis: tbarnikis@ryerson.ca Rachel Berman: rcberman@ryerson.ca (416) 979-5000 ext. 7695

\section{PURPOSE OF THE STUDY}

The purpose of this study is to explore how children perceive and compare their experience in two different educational settings. The study aims to establish children as experts on their own lived experiences. Through interviews and drawings children will reflect on their perceptions of their experiences in different educational settings.

\section{DESCRIPTION OF THE STUDY AND YOUR PARTICIPATION}

\section{If you volunteer to participate in this study, you will be asked to do the following things:}

Tiffany is looking to recruit five children to participate in this study. This form is seeking your permission for your child to participate in the research study. Your child will be asked to participate in an interview at your home. The interview will last approximately 20-30 minutes and will involve:

- Answering some open-ended questions (e.g. "Tell me about your classroom? Do you remember your first day of school? Can you tell me what you remember about the ELC?

- Looking at some photographs of the child's former classroom

- Drawing pictures for the child's former and present classroom

At the conclusion of the research project, a summary of findings will be available to children and their families. All names of children and school will be replaced by pseudonyms. 


\section{POTENTIAL RISKS AND DISCOMFORTS}

The potential risks of this study are very low. Tiffany will be asking the children to reflect on experiences. A participant may reflect on unpleasant memories while responding to a questionnaire or interview and become upset or feel anxious. The participant will be informed of that they may take a break, choose not to answer a particular question, or discontinue participating, if they wish, for any reason. Tiffany is a registered Early Childhood educator and is confident in supporting children with any discomfort they may experience.

\section{POTENTIAL BENEFITS TO PARTICIPANTS AND/OR TO SOCIETY}

This study aims to recognise children as expert on their lived experience. The information generated from this study may initiate conversation and future research on children's perceptions of different educational settings and practices.

I cannot guarantee, however, that you will receive any benefits from participating in this study.

You will not be paid to participate in this study, however, you child will receive a small gift and certificate of appreciation.

\section{CONFIDENTIALITY}

Only Tiffany Barnikis and Rachel Berman will have access to the data. All the participant's names will be removed from the data and pseudonyms will be given. The audio files, interview transcripts, field notes, and digital photographs will be kept on my password-protected computer. All raw data will be kept for five years and then destroyed.

\section{VOLUNTARY PARTICIPATION AND WITHDRAWAL}

Participation in this study is voluntary. You can choose whether your child is involved in this study or not. If you volunteer to be in this study, you may withdraw your child at any time without consequences of any kind. If you, or your child, choose to withdraw from this study you may also choose to withdraw your data from the study. Your child may also choose not to answer any question(s) and still remain in the study. Your choice of whether or not to participate will not influence your future relations with Ryerson University, the School of Early Childhood's Early Learning Centre, or Tiffany Barnikis.

\section{QUESTIONS ABOUT THE STUDY}

If you have any questions about the research now, please ask. If you have questions later about the research, you may contact:

Tiffany Barnikis tbarnikis@ryerson.ca

Rachel Berman rcberman@ryerson.ca (416) 979-5000 ext. 7695 
This study has been reviewed by the Ryerson University Research Ethics Board. If you have questions regarding your rights as a research participant in this study, please contact:

Toni Fletcher, Research Ethics Coordinator

Research Ethics Board

Office of the Vice President, Research and Innovation

Ryerson University

350 Victoria Street

Toronto, Ontario M5B 2K3

416-979-5042 or toni.fletcher@ryerson.ca

\section{SIGNATURE OF RESEARCH PARTICIPANT}

Your signature below indicates that you have read the information in this agreement and have had a chance to ask any questions you have about the study "Children's Comparison of Two Educational Environments" as described herein. Your questions have been answered to your satisfaction, and you agree to participate in this study. You have been given a copy of this form.

Name of Participant (please print)

Name of Parent/guardian of Participant

Date:

Signature of Parent/guardian of Participant 
Your signature below indicates that you give consent for your child to be audio-recorded

Name of Participant (please print)

Name of Parent/guardian of Participant

Date:

Signature of Parent/guardian of Participant 


\section{Appendix C: Assent Form}

\section{Assent Agreement}

\section{CHILDREN'S COMPARISON OF TWO EDUCATIONAL ENVIRONMENTS}

I am ok with talking, looking at pictures, and drawing pictures about my school and classroom with Tiffany.

It's OK by me that:

1. No one else will know what we talk about.

2. What we talk about will be taped with a tape recorder.

3. Only Tiffany and her teacher, Rachel, will listen to the tapes. Tiffany will protect the tapes by keeping them safe.

4. I can stop talking, drawing or looking at pictures any time. To do this is I can just say, "stop now" or I can say, "next question."

5. I can stop at anytime without anyone being upset or angry with me.

6. Tiffany might talk to someone in charge if they are worried about my safety.

7. My mom or dad have said it's OK for me to do this but if I don't want to, it's OK for me to just say so.

My name:

My signature or special mark:

Today's date: 


\section{Appendix D: Conversation Guide}

\section{Conversation Guide - Semi-structured - With Prompts.}

1) Tell me about your classroom?

- That sounds interesting. Can you tell me a bit more about that?

2) What do you like about school?

- What is it about that, which you like?

- What is your favourite part of the day?

3) Is there anything you don't like about school?

- Can you tell me a bit about why you don't like that?

4) Tell me about your teacher?

- Can you tell me another story about him/her?

5) If there were a new child starting in your class, what would you want him or her to know about your class or school before they started?

- What could you tell them to help them get settled in the classroom?

6) I have never been to your school, could you draw me a picture of what your classroom looks like?

- Can you tell me a bit more about your drawing?

7) Do you remember your first day of school?

- Can you tell me a bit more about it?

8) Can you draw me a picture of what you remember about [name of university laboratory school]?

- Can you tell me a bit more about your drawing? 
9) I have some pictures and map of your old classroom. Can you tell me about what you remember about [name of university laboratory school]?

- Do you remember anything else?

10) Do you remember what your favourite thing there was?

- What was your favourite part of the day?

11) Was there anything that you didn't like there?

- What didn't you like about that?

12) What do you remember about the teacher there?

- Can you tell me more?

13) How are the school you go to now and [name of university laboratory school] the same?

- Is there anything else that is the same?

14) How are the school you go to now and [name of university laboratory school] different?

- Why do you think that is different?

Thanks, is there anything else you would like me to know about your school you are in now or [name of university laboratory school]? 


\section{Appendix E: Photographs of the University Laboratory School}
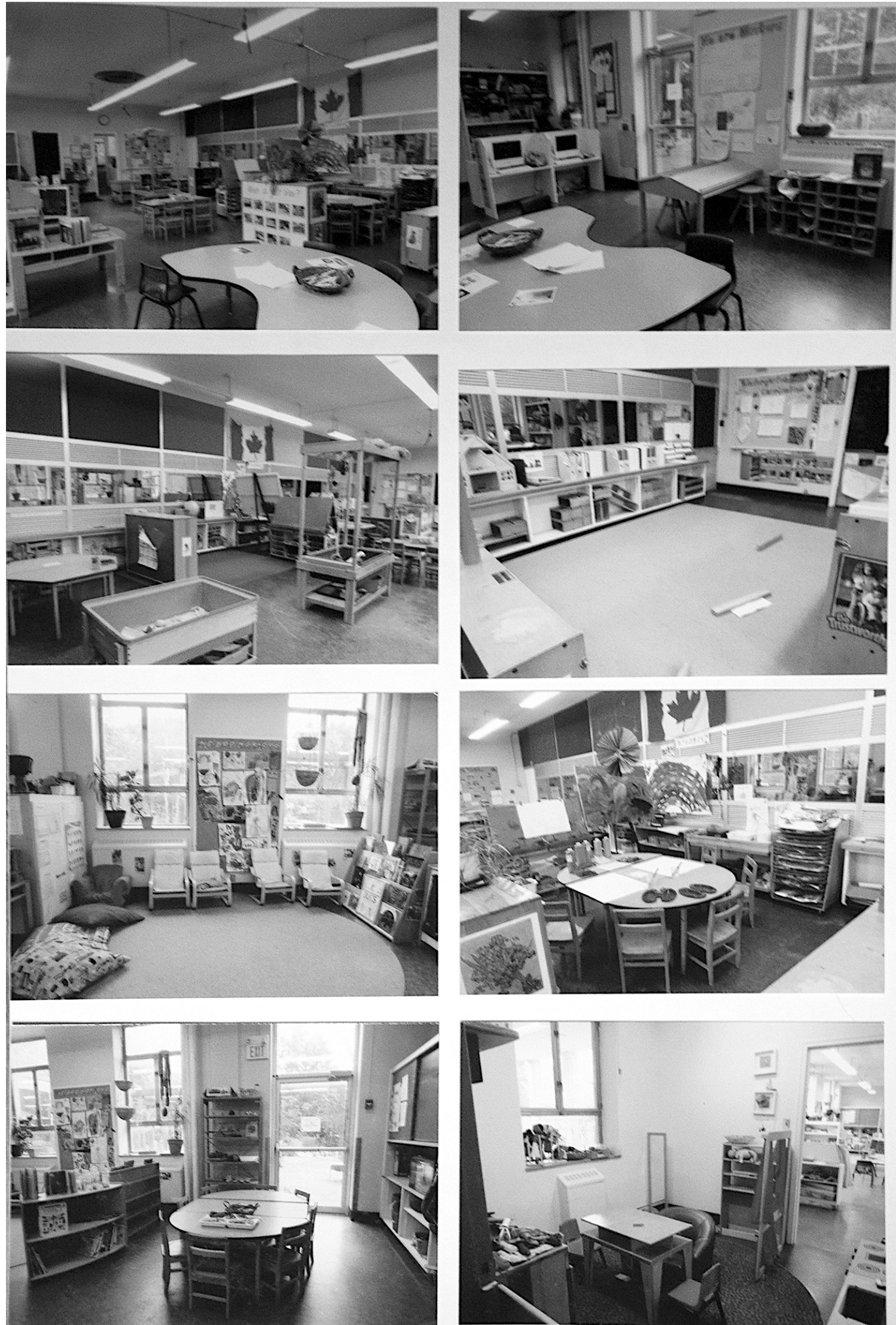

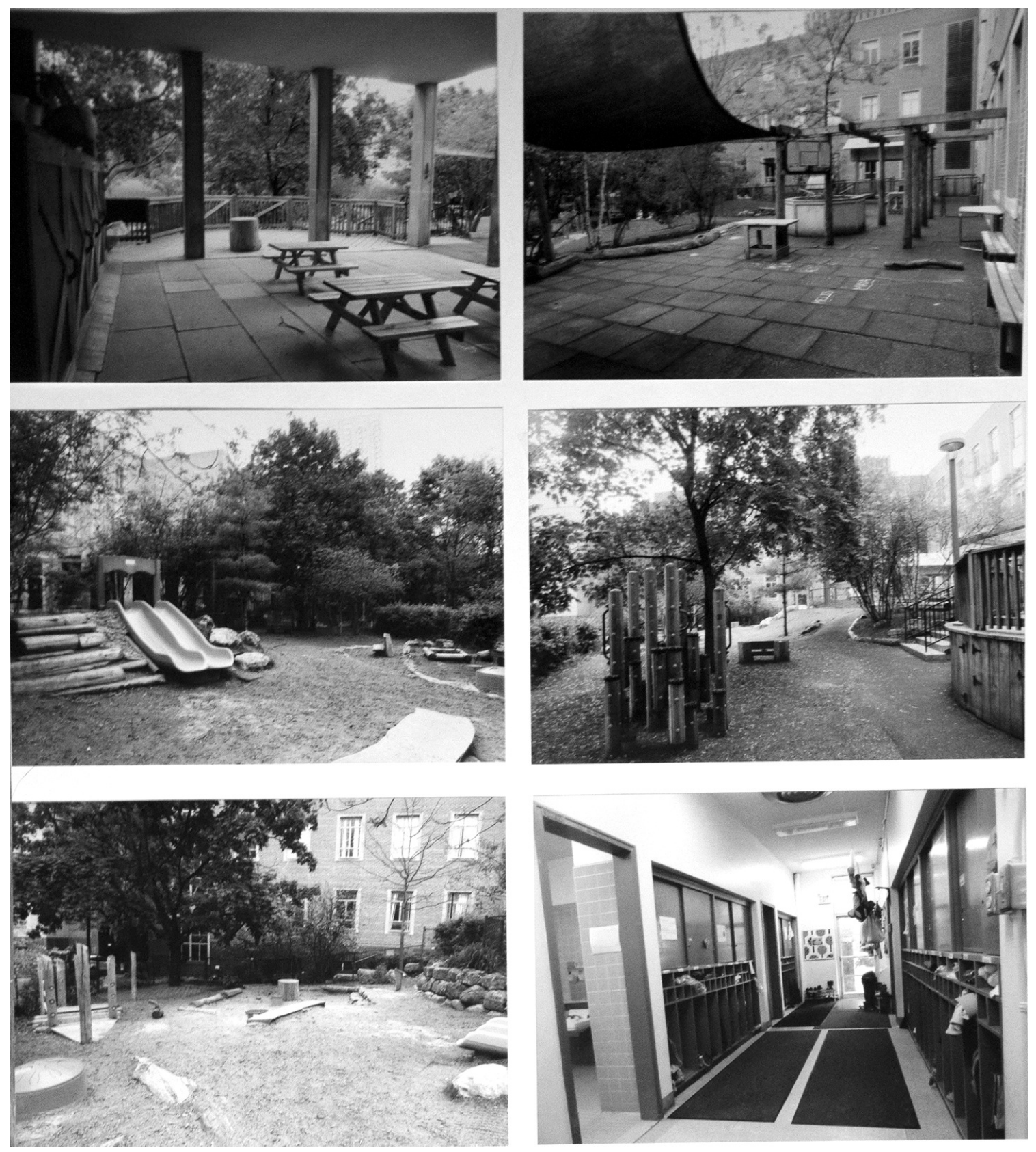


\section{References}

Anfara, V. (2008). Theoretical Frameworks. In Lisa M. Given (Ed.), The SAGE Encyclopaedia of qualitative research methods. (pp. 870-874). Thousand Oaks, CA: SAGE Publications, Inc. doi: http://dx.doi.org/10.4135/9781412963909.n453

Ariès, P. (1962). Centuries of childhood: A social history of family life. (R. Baldick, Trans.). New York, NY: Alfred A. Knopf, Inc. (Original work published 1960)

Barbour, N. E. (2003). The early history of child development laboratory programs. In B. A. McBride \& N. E. Barbour (Eds.), Bridging the gap between theory, research and practice: The role of child development laboratory programs in early childhood education (pp. 9-29). Oxford, UK: Elsevier Ltd.

Barnikis, T. (2013). Teachers' perceptions about working in a university laboratory school. Unpublished manuscript. Department of Early Childhood Studies, Ryerson University. Toronto: ON.

Basit, T. N. (2010). Conducting research in educational contexts. London, UK: Continuum International Publishing Group.

Burke, C. (2005)."Play in focus": Children researching their own spaces and places for play. Children, Youth and Environments, 15(1), 27-53. Retrieved from http://www.jstor.org/stable/10.7721/chilyoutenvi.15.1.0027

Cameron, H. (2005). Asking the tough questions: A guide to ethical practices in interviewing young children. Early Child Development and Care, 175(6), 597-610. doi:10.1080/03004430500131387

Catt, H., \& Murphy, M. (2003). What voice for the people? Categorising methods of public consultation. Australian Journal of Political Science, 38(3), 407-421. doi:10.1080/1036114032000133967 
Ceglowski, D. A. \& Bacigalupa, C. (2007). "[I] play a lot": Children's perceptions of child care. Journal of Research in Childhood Education, 22(2), 173. Retrieved from http://ezproxy.lib.ryerson.ca/login?url=http://search.proquest.com.ezproxy.lib.ryerson.ca/ docview/203891474?accountid=13631

Cheah, C. S. \& Chirkov, V. (2008). Parent's personal and cultural beliefs regarding young children: A cross-cultural study of Aboriginal and Euro-Canadian mothers. Journal of Cross-Cultural Psychology, 39, 402-423.

Cole, A. G. (2009). Mapping students' lives: Children's geographies, teaching and learning. The Educational Forum, 73(1), 20-32. doi:10.1080/0013172080253957

Cooney, M. H., Gupton, P., \& O'Laughlin, M. (2000). Blurring the lines of play and work to create blended classroom learning experiences. Early Childhood Education Journal. 27(3), 165-171. doi: 10.1007/BF02694230

Corsaro, W. A. (2015). The sociology of childhood (4th ed.). Thousand Oaks, CA: Sage Publications.

Cox, S. (2005). Intention and meaning in young children's drawing. International Journal of Art \& Design Education, 24(2), 115-125. doi:10.1111/j.1476-8070.2005.00432.x

Creswell, J. (2014). Research design: Qualitative, quantitative, and mixed method approaches. (4th ed.). Thousand Oaks, CA: Sage Publications.

Devine, D. (2002). Children's citizenship and the structuring of adult-child relations in the primary school. Childhood, 9(3), 303-320. doi:10.1177/0907568202009003044

Dewey, J. (1900). The school and society; Being three lectures. (3rd ed.). Chicago, IL: The University of Chicago Press. Retrieved from http://hdl.handle.net/2027/uc2.ark:/13960/t2p55gp3c 
Dewey, J. (1916). Democracy and education: An introduction to the philosophy of education. New York, NY: Macmillan.

Di Santo, A., \& Berman, R. (2012). Beyond the preschool years: Children's perceptions about starting kindergarten. Children \& Society, 26(6), 469-479. doi:10.1111/j.1099-0860.2011.00360.x

Dockett, S., Einarsdottir, J., \& Perry, B. (2009). Researching with children: Ethical tensions. Journal of Early Childhood Research, 7(3), 283-298. doi:10.1177/1476718X09336971

Dockett, S., \& Perry, B. (1999). Starting school: What do the children say? Early Child Development and Care, 159(1), 107-119. doi:10.1080/0300443991590109

Dockett, S., \& Perry, B. (2005). Researching with children: Insights from the starting school research project. Early Child Development and Care, 175(6), 507-521. doi:10.1080/03004430500131312

Dockett, S. \& Perry, B. (2005). 'You need to know how to play safe': Children's experiences of starting school, Contemporary issues in early childhood, 6(1), 4-18. Retrieved from http://dx.doi.org/10.2304/ciec.2005.6.1.7

Dockett, S., \& Perry, B. (2013). Siblings and buddies: Providing expert advice about starting school. International Journal of Early Years Education, 21(4), 348-361. doi:10.1080/09669760.2013.867837

Donmoyer, R. (2006). Take my paradigm ... please! The legacy of Kuhn's construct in educational research. International Journal of Qualitative Studies in Education, 19(1), 11-34. doi:10.1080/09518390500450177

Einarsdottir, J. (2008). Children's and parents' perspectives on the purposes of playschool in Iceland. International Journal of Educational Research, 47(5), 283-291. doi:10.1016/j.ijer.2008.12.007 
Einarsdottir, J. (2010). Children's experiences of the first year of primary school. European Early Childhood Education Research Journal, 18(2), 163-180. doi:10.1080/13502931003784370

Einarsdottir, J., Dockett, S., \& Perry, B. (2009). Making meaning: Children's perspectives expressed through drawings. Early Child Development and Care, 179(2), 217-232. doi:10.1080/03004430802666999

Erickson, P., Gray, N., Wesley, B., \& Dunagan, E. (2012) Why parents choose laboratory schools for their children," NALS Journal, 2(2), Article 2, 1-8. Retrieved from http://digitalcommons.ric.edu/nals/vol2/iss $2 / 2$

Fielding, S. 2000. Walking on the left!: children's geographies and the primary school. In Sarah Holloway and Gill Valentine (Eds.) Children's Geographies: Playing, Living and Learning (pp. 230-244). New York, NY: Routledge.

Foucault, M. (1979). Discipline and punish: The birth of the prison. (A. Sheridan, Trans.). New York, NY: Vintage Books.

Freire, P. (2000). Pedagogy of the oppressed, (30th Anniversary ed.). (M. Bergman Ramos, Trans.). New York, NY: Continuum.

Fullan, M. (2001). The new meaning of educational change. (3rd Ed). New york, NY: Teachers College Press.

Gardiner, H., \& Kosmitzki, C. (2011). Lives across cultures: Cross-cultural human development (5th ed.). Boston. MA: Allyn \& Bacon.

Gillespie, J. (2012). Being and becoming: Writing children into planning theory. Planning Theory, 12(1), 64-80. doi: 10.1177/1473095212441696 
Glazzard, J. (2012). Tuning into children's voices: Exploring the perceptions of primary aged children about their education in one primary school in England. International Journal of Education, 4(3), 49. doi:10.5296/ije.v4i3.1933

Goodman, J. (1994). "Work" versus "play" and early childhood care. Child and Youth Care Forum, 23(3), 177-196. doi:10.1007/BF02209227

Graue, M. E. \& Walsh, J. W. (1998). Studying children in context: Theories, methods and ethics. Thousand Oaks, CA: Sage Publications.

Grover, S. (2004). Why won't they listen to us? Childhood, 11(1), 81-93. doi:10.1177/0907568204040186

Guba, E. (1981). Criteria for assessing the trustworthiness of naturalistic inquiries. ERIC/ECTJ Annual Review Paper, 29(2), 75-91. doi:10.1007/BF02766777

Haynes, K. (2010). Other lives in accounting: Critical reflections on oral history methodology in action. Critical Perspectives on Accounting, 21(3), 221-231. doi:10.1016/j.cpa.2009.11.002

Harry, B. (1997). Leaning forward or bending over backwards: Cultural reciprocity in working with families. Journal of Early Intervention, 21(1), 62-72.

doi:10.1177/105381519702100107

Kincheloe, J. (2011). The complex politics of McDonald's and the new childhood: Colonizing kidworld. International Critical Childhood Policy Studies, 4(1), 1-46. http://journals.sfu.ca/iccps/index.php/childhoods/arti cle/view/39/32

King, N. R. (1979). Play: The kindergartens' perspective. The Elementary School Journal, 80(2), 80-87. Retrieved from http://www.jstor.org/discover/10.2307/1001284?uid=3739448\&uid=2129\&uid=2\&uid=7 0\&uid=3737720\&uid $=4 \&$ sid $=21103951582173$ 
Kincheloe, J. (2011). The complex politics of McDonald's and the new childhood: Colonizing kidworld. International Critical Childhood Policy Studies, 4(1), 1-46. http://journals.sfu.ca/iccps/index.php/childhoods/arti cle/view/39/32

Kumar, A. (2012). Using phenomenological research methods in qualitative health research. International Journal of Human Sciences, 9(2), 790-804. http://www.j humansciences.com/ojs/index.php/IJHS/article/view/2343/954\#.UlP_nhYkVlI

Hellström, T. (2008). Transferability and naturalistic generalization: New generalizability concepts for social science or old wine in new bottles? Quality \& Quantity, 42(3), 321337. doi:10.1007/s11135-006-9048-0

Lee, K., \& Johnson A. S. (2007). Child development in cultural contexts: Implications of cultural psychology for early childhood teacher education. Early Childhood Education Journal, 35 (3), 233-243. doi: 10.1007/s10643-007-0202-7

Leitch, R. (2008). Creatively researching children's narratives through images and drawings. In P. Thomson (Ed.) Doing visual research with children and young people, (pp. 37-57). New York, NY: Routledge,

Lincoln, Y. \& Guba, E. (2003). Paradigmatic controversies, contradictions and emerging confluences. In N. K. Denzin \& Y. S. Lincoln (Eds.), The landscape of qualitative research: Theories and issues (2nd ed.) (pp. 253-291). Thousand Oak, CA: Sage Publications.

Matthews, H., \& Limb, M. (1999). Defining an agenda for the geography of children: Review and prospect. Progress in Human Geography, 23(1), 61-90. doi:10.1191/030913299670961492

Matthews, S. H., (2007). A window on the "new" sociology of childhood. Sociology Compass 1(1), 322-334. Retrieved from http://www.jstor.org/stable/1001284 
Mayall, B. (1994). Introduction. In B. Mayall (Ed.) Children's childhoods: Observed and experienced, (pp. 1-12 London, England: Falmer Press.

Mayall, B. (2002). Towards a sociology for childhood: Thinking from children's lives. Buckingham, England: Open University Press.

Mayall, B. (2008). Conversations with children: Working with generational issues. In P. Christensen \& A. James (Eds.) Research with children: Perspectives and practices (2nd Edition), (pp. 109-124). New York, NY: Routledge.

McBride, B. \& Baumgartner, J. (2006). The changing profile of teaching, research and outreach activities in lab school programs. In B. A. McBride \& N. E. Barbour (Eds.), Bridging the gap between theory, research and practice: The role of child development laboratory programs in early childhood education (pp. 9-29). Oxford, UK: Elsevier Ltd.

McBride, B. A., Groves, M., Barbour, N., Horm, D., Stremmel, A., Lash, M., .. Toussaint, S. (2012). Child development laboratory schools as generators of knowledge in early childhood education: New models and approaches. Early Education \& Development, 23(2), 153-164. doi: 10.1080/10409289.2012.651068

McBride, B. A., \& Hicks, T. (1998). Parental and staff member perceptions of lab school functions and program quality. Early Child Development and Care, 143(1), 21-32. doi: $10.1080 / 0300443981430102$

Millei, Z. (2012). Thinking differently about guidance: Power, children's autonomy and democratic environments. Journal of Early Childhood Research, 10(1), 88-99. doi:10.1177/1476718X11406243

Millei, Z., \& Raby, R. (2010) Embodied logic: Understanding discipline through constituting the subject of discipline. In Z. Millei, T.G. Griffiths, R.J. Parkes (Eds.) Re-theorizing discipline in education (pp. 27-42). New York, NY: Peter Lang Publishing. 
Milner, H. (2013). Analyzing poverty, learning, and teaching through a critical race theory lens. Review of Research in Education, 37(1), 1-53. doi:10.3102/0091732X12459720

Moss, P. (2007). Bringing politics into the nursery: Early childhood education as a democratic practice. European Early Childhood Education Research Journal, 15(1), 5-20. doi:10.1080/13502930601046620

Mukherji, P. \& Albon, D. (2010). Research Methods in Early Childhood: An Introductory Guide. Thousand Oaks, CA: Sage Publications.

Noyes, A. (2005). Pupil voice: purpose, power and possibilities for democratic schooling. British Educational Research Journal, 31(4), 533-540. doi:10.1080/01411920500153614

Olwig, K. F. (2011). Children's sociality: The civilizing project in the Danish kindergarten. Social Analysis, 55(2), 121-141. Retrieved from http://ezproxy.lib.ryerson.ca/login?url=http://search.proquest.com/docview/892574445?ac countid=13631

Ontario Ministry of Education (2010). Full-day early learning-kindergarten program: Draft version. ON: Queen's Printer for Ontario. Retrieved from: http://www.edu.gov.on.ca/eng/curriculum/elementary/kindergarten_english_june3.pdf Ontario Ministry of Education (2012). Foundations for a Healthy School. ON: Queen’s Printer for Ontario. Retrieved from http://www.edu.gov.on.ca/eng/Healthyschools/foundations.pdf

Pech, S. (2013). Peer pals: Supporting positive social-emotional behaviors in a kindergarten classroom. Childhood Education, 89(4), 217. Retrieved from http://ezproxy.lib.ryerson.ca/login?url=http://search.proquest.com/docview/1492879347? accountid=13631 
Peters, S. (2003). "I didn't expect that I would get tons of friends... More each day": Children's experiences of friendship during the transition to school. Early Years: An International Research Journal, 23(1), 45-53. doi:10.1080/0957514032000045564

Poimenidou, M. \& Papadopoulou, M. (2013). Shaping consciousness in kindergarten. Conformity to school norms through the formation of a child's story. International Education Studies, 6(1), 166-173. Retrieved from http://ezproxy.lib.ryerson.ca/login?url=http://search.proquest.com/docview/1447232773? accountid $=13631$

Prout, A. \& James, A. (1997). A new paradigm for the sociology of childhood? Provenance, promise and problems. In A. Prout \& A. James (Eds.), Constructing and reconstructing childhood: Contemporary issues in the sociological study of childhood (2nd ed.) (pp. 7 32). London, England: Falmer Press.

Punch, S. (2002). Research with children. Childhood, 9(3), 321-341. doi:10.1177/0907568202009003005

Qvortrup, J. (2004). Editorial. Childhood, 11(3), 267-273. doi:10.1177/0907568204044884

Raby, R. (2008). Frustrated, resigned, outspoken: Students' engagement with school rules and some implications for participatory citizenship. The International Journal of Children's Rights, 16(1), 77-77. doi:10.1163/092755608X267148

Ravitch, S. \& Riggan, M. (2012). Reason \& rigor: How conceptual frameworks guide research. Thousand Oaks, CA: Sage Publications Inc.

Reason, P. (1988). Introduction. In P. Reason (Ed.), Human inquiry in action: Developments in new paradigm research (pp. 1-17). Thousand Oaks, CA: Sage Publications.

Riessman, C. K. (2008). Narrative methods for the human sciences. Thousand Oaks, CA: Sage Publications. 
Rocco, T., \& Plakhotnik, M. (2009). Literature reviews, conceptual frameworks, and theoretical frameworks: Terms, functions, and distinctions. Human Resource Development Review, 8(1), 120-130. doi:10.1177/1534484309332617

Rogoff, B. (1990). Apprenticeship in thinking: Cognitive development in social context. New York, NY: Oxford University Press.

Rogoff, B. (2003). The cultural nature of human development. New York, NY: Oxford University Press.

Sears, A. \& Cairns, J. (2010). A good book in theory: Making sense through inquiry. (2nd ed.). Toronto, ON: University of Toronto Press.

Schneider, C. J. (2004). Integrating critical race theory and postmodernism implications of race, class, and gender. Critical Criminology, 12(1), 87-103.

doi:10.1023/B:CRIT.0000024440.94130.59

Singal, N. \& Swann, M. (2009). Children's perceptions of themselves as learner inside and outside school. Research Papers in Education, 26 (4), 469-484. doi: $10.1080 / 02671520903281617]$

Skelton, A. (1997). Studying hidden curricula: Developing a perspective in the light of postmodern insights. Curriculum Studies, 5(2), 177-193.

doi:10.1080/14681369700200007

Spratling, R., Coke, S., \& Minick, P. (2012). Qualitative data collection with children. Applied Nursing Research, 25(1), 47-53. doi:10.1016/j.apnr.2010.02.005

Stafford, A., Laybourn, A., Hill, M. and Walker, M. (2003), 'Having a say': children and young people talk about consultation. Children \& Society, 17: 361-373. doi: 10.1002/CHI.758 
Stephenson, A. (2009). Horses in the sandpit: Photography, prolonged involvement and 'stepping back' as strategies for listening to children's voices. Early Child Development and Care, 179(2), 131-141. doi:10.1080/03004430802667047

Theobald, M., Danby, S., \& Ailwood, J. (2011). Child participation in the early years: Challenges for education. Australasian Journal of Early Childhood, 36(3), 19-26.

Thornberg, R. (2010). School democratic meetings: Pupil control discourse in disguise. Teaching and Teacher Education, 26(4), 924-932. doi:10.1016/j.tate.2009.10.033

Thornberg, R. \& Elvstrand, H. (2012). Children's experiences of democracy, participation, and trust in school. International Journal of Educational Research, 53, 44-54.

doi:10.1016/j.ijer.2011.12.010

United Nations (1989) United Nations Convention on the Rights of the Child. Geneva, Switzerland: United Nations.

Whittemore, R., Chase, S., \& Mandle, C. (2001). Validity in qualitative research. Qualitative Health Research, 11(4), 522-537. doi:10.1177/104973201129119299

Woodhead, M. (2005). Early childhood development: A question of rights. International Journal of Early Childhood, 37(3), 79-98. doi:10.1007/BF03168347 